\title{
Deformable metal-organic framework nanosheets for heterogeneous catalytic reactions
}

\author{
Chuanhui Huang ${ }^{1,4 \varsigma}$, Zhihong Guo ${ }^{2,4 \varsigma}$, Xu Zheng', Xiangyu Chen', Zhenjie Xue ${ }^{1,4}$, \\ Shuwei Zhang ${ }^{1}$, Xiao $\mathrm{Li}^{1}$, Bo Guan ${ }^{1}$, Xiang $\mathrm{Li}^{1}$, Guoqing Hu${ }^{3 *}$, and Tie Wang ${ }^{1,4 *}$
}

${ }^{1}$ Beijing National Laboratory for Molecular Sciences, Key Laboratory of Analytical Chemistry for Living Biosystems Institute of Chemistry, Chinese Academy of Sciences, \#2 Zhongguancun, North First Street, Beijing 100190, China. ${ }^{2}$ The State Key Laboratory of Nonlinear Mechanics (LNM), Institute of Mechanics, Chinese Academy of Sciences, Beijing 100190, China. ${ }^{3}$ Department of Engineering Mechanics \& State Key Laboratory of Fluid Power and Mechatronic Systems, Zhejiang University, Hangzhou 310027, China. ${ }^{4}$ University of Chinese Academy of Sciences, Beijing 100049, China. 


\section{Method}

\section{Materials}

All chemicals used were at least of analytical grade. Copper nitrate trihydrate $\left(\mathrm{Cu}\left(\mathrm{NO}_{3}\right)_{2} \cdot 3 \mathrm{H}_{2} \mathrm{O}\right)$, 2-aminoethanol $\left(\mathrm{NH}_{2}-\mathrm{CH}_{2} \mathrm{CH}_{2} \mathrm{OH}\right)$, terephthalic acid $\left(\mathrm{H}_{2} \mathrm{BDC}\right)$, potassium tetrachloropalladate $\left(\mathrm{K}_{2} \mathrm{PdCl}_{4}, \mathrm{GR}\right)$, L-ascorbic acid (AR), Polyvinylpyrrolidone (PVP, average $\mathrm{Mw}=58000$ ) were purchased from Aladdin (Shanghai, China). Potassium bromide $(\mathrm{KBr}, 99 \%)$, potassium chloride $(\mathrm{KCl}, 99 \%)$, 1-hexene and cyclooctene were purchased from Energy Chemical, The supports were Nylon 66 microporous membranes (Jin teng) with an average pore size of $c a 220 \mathrm{~nm}$ and porosity of 50\%. Ultrapure water (18.2 $\mathrm{M} \Omega$ ) produced by a Millipore direct- $Q$ system (Millipore) was used throughout the experiments.Commercial reagents were purchased from Sigma-Aldrich (ACS grade) and used as received unless otherwise noted

\section{Characterisation}

The products were characterised by XRD (model D/MAX2500; Rigaku, Tokyo, Japan) with $\mathrm{Cu}-\mathrm{Ka}$ radiation at a scanning rate of $3 \% \mathrm{~min}$. The FT-IR spectra were measured using a Nicolet 6700 instrument (Thermo Fisher Scientific, Waltham, MA, USA). The morphologies were characterised by a Hitachi S-4800 scanning electron microscopy (SEM; Hitachi, Tokyo, Japan) equipped for EDX analysis. The TEM images were obtained using Hitachi H-800 and JEOL JEM-2010 (JEOL, Tokyo, Japan) instruments at an accelerating voltage of $200 \mathrm{kV}$. The content of Pd was quantified by an Optima 7300 DV inductively coupled plasma atomic emission spectrometer (ICP-AES). The number of accessible Pd sites was estimated by $\mathrm{CO}$ titration using a fully automated chemisorption analyzer (Micromeritics, Autochem II 2920) at 293 K. Prior to CO titration, the catalysts were treated at $423 \mathrm{~K}$ for $60 \mathrm{~min}$ and then cooled to $293 \mathrm{~K}$ under a hydrogen flow. The CO uptake was measured by the decrease in the peak areas induced by chemsorption compared with the area of a calibrated volume. The metal dispersion was calculated assuming a stoichiometry of one $\mathrm{CO}$ molecule per surface metal atom. The surface area and pore diameter were determined with a physisorption analyser (model ASAP 2020M; Micromeritics, Norcross, GA, USA) at $-196^{\circ} \mathrm{C}$. Before measurements, samples were degassed in vacuo at $180^{\circ} \mathrm{C}$ for at least $8 \mathrm{~h}$. The 
Brunner-Emmet-Teller (BET) method was used to calculate the specific surface areas (SBET) using adsorption data at $P / P_{0}$ of $0.05-0.30$. The pore size distributions (PSDs) were derived from the adsorption branches of the isotherms using the Barrett-Joyner-Halenda (BJH) model. The total pore volume $\left(\mathrm{V}_{\mathrm{t}}\right)$ was estimated from the adsorbed amount at $P / P_{0}$ of 0.995. Thermogravimetric analysis (TGA) was carried out using a Pyris 1 TGA (PerkinElmer, Waltham, MA, USA) with a nitrogen flow of $10 \mathrm{~mL} \mathrm{~min}{ }^{-1}$. Quantitative mechanical property mapping was carried out using a Dimension FastScan AFM (Bruker AXS Corporation, Santa Barbara, CA, USA), operated under the peak-force taping mode (PeakForce QNM), in which the applied force was $100 \mathrm{nN}$ and the scan rate was set at $1 \mathrm{~Hz}$. The spring constant of the cantilever was $26 \mathrm{~N} \mathrm{~m}^{-1}$, as determined by measuring the free resonance frequency in air. The radius of the standard AFM probe was $18 \mathrm{~nm}$. The spatial distribution of the Young's modulus across the nanowire surface was determined from the AFM load-displacement curves by applying the Derjaguin-Muller-Toporov (DMT) model. The cantilever spring constant and sensitivity were calibrated before and after each experiment. Data processing was performed using the commercial Nanoscope Analysis software (Bruker AXS Corporation).

\section{Adsorption experiments}

Before adsorption, MOF crystals were dried overnight at $120^{\circ} \mathrm{C}$ under vacuum, then kept in a desiccator. In a typical adsorption experiment, a $10 \mathrm{~mL}$ vial equipped with Teflon-lined screw cap received a weighed amount of adsorbent $(10.0 \pm 0.2 \mathrm{mg})$, followed by adding 5.0 $\mathrm{mL}$ of phenol red ethanolic solution at room temperature. The mixture was well oscillated for $12 \mathrm{~h}$ at $298 \mathrm{~K}$. After adsorption, the solution was separated through centrifugation at $9000 \mathrm{rpm}$ for $2 \mathrm{~min}$ and analyzed for the concentration of residual phenol red using a UV spectrophotometer at the calibrated maximum wavelength of $420 \mathrm{~nm}$.

Kinetic experiments were conducted using $200 \mathrm{mg} \mathrm{L}^{-1}$ of phenol red, Samples were collected at different pre-determined time intervals to evaluate the residual phenol red concentrations (as determined previously) in the ethanol solution. Control experiments were performed with blanks containing no phenol red under the same conditions as for the phenol red solution. Each data point was run in triplicate. The equilibrium adsorption capacity $Q_{e}$ was 
calculated according to Eq. (1):

$$
Q_{e}=\frac{\left(C_{0}-C_{e}\right) V}{m}
$$

Where the $C_{o}$ and $C_{e}\left(\mathrm{mg} \mathrm{L}^{-1}\right)$ are initial and equilibrium concentrations of phenol red, respectively. $\mathrm{V}(\mathrm{L})$ was the volume of the solution, and $\mathrm{m}(\mathrm{g})$ was the mass of sorbent.

\section{Numerical simulations}

We have carried out numerical simulations to investigate how the passive motion of the nanosheets enhances mixing. A commercial modeling software, COMSOL Multiphysics (version 5.4, COMSOL 1td, USA), was used to simulate the fluid-structure interaction between the flow and the nanosheet in two dimensions. The transport of the reactants was coupled with the flow field at the same time to show the effect of the nanosheets on mixing performance under different conditions. The Arbitrary Lagrangian-Eulerian (ALE) technique was used to handle the deformation of the nanosheet and the force transmission at the boundaries between the fluid and the solid. Figure S15a-S15b show the setup of the numerical model. In this example, the computing domain is $5 \mu \mathrm{m}$ high and $8 \mu \mathrm{m}$ long. Five configurations were considered here. First, there are two kinds of geometric model, one model for nanosheet (based on the numerical simulation of boundary conditions are divided into different flexible nanosheet model and rigid nanosheet model). The geometric shape of the nanosheets is $500 \mathrm{~nm}$ in length ( $\mathrm{Y}$ direction), $25 \mathrm{~nm}$ in width (X direction), $1500 \mathrm{~nm}$ in height ( $\mathrm{Z}$ direction), and the elastic modulus $\mathrm{E}$ is $0.2 \mathrm{GPa}$. The leftmost nanosheet is $2.5 \mu \mathrm{m}$ away from the left boundary of the channel. Another geometric shape has a bulk of $3 \mu \mathrm{m}$ wide and $1.5 \mu \mathrm{m}$ high at the channel bottom, which is $2.5 \mu \mathrm{m}$ away from the left boundary of the channel. The geometric shape of the bulk is $500 \mathrm{~nm}$ in length (Y direction), $3000 \mathrm{~nm}$ in width ( $\mathrm{X}$ direction), $1500 \mathrm{~nm}$ in height ( $\mathrm{Z}$ direction), and elastic modulus is $20 \mathrm{GPa}$. Then, In order to consider the influence of nanosheet height on the transport of matter in chemical reactions, three models with heights of $0.375 \mu \mathrm{m}, 0.75 \mu \mathrm{m}$ and $2.25 \mu \mathrm{m}$ were also established. Nanosheet/bulk is modeled as linear elastic solid materials based on the physical properties of MOF. The ethyl acetate solution was considered a Newtonian fluid in the simulation. For the flow field, we set the left boundary of the channel as the inlet boundary where the inlet normal velocity is given by Eq. (2) and the right boundary as the exit boundary. No-slip 
boundary conditions are imposed at all the other boundaries. For transport of reactants (hexene and hydrogen), the top wall of channel is set as the concentration inlet boundary. Flux-free boundary conditions are set at all the other boundaries. Automatic remeshing is used to capture the dynamic motion of the flexible nanosheets. Figures S15c-S15d show the initial grids of the flexible nanosheet and the remeshed grids when the maximum deformation is reached.

$$
u_{i n}=\frac{U \cdot t^{2}}{\sqrt{\left(0.04-t^{2}\right)^{2}+(0.1 t)^{2}}}
$$

As shown in Figure S16, the concentration at the surfaces of the nanosheets/bulk marked in red in the figure is integrated to obtain the mass of the reactants that the nanosheet/body film can contact. The more the mass of the reactants can be transported to the reaction sites, the higher the reaction is.

As described in the text, nanosheet and bulk are modeled as cantilever beams and are subjected to uniform shear forces in the flow field (Figure S13a). For the convenience of calculation, the uniform load is simplified to the concentrated force load (Figure S13b). Based on Eq. (3) and Eq. (4), the degree of deformation of nanosheet and bulk in the case of small deformation can be calculated. However, since the elastic modulus of nanosheet is small and the force deformation is large, large deformation of nanosheet must be considered. According to Eq. (5) in Zhao's theory ${ }^{1}$ and using the MATLAB (The MathWorks, Inc. USA) software, the final nanosheet deformation result is obtained. All results are shown in the Figure 4a.

$$
\begin{aligned}
& y=\frac{F l^{3}}{3 E I} \\
& y=\frac{M l^{2}}{2 E I} \\
& y=\frac{F l^{3}}{9 E I+F l^{2}}
\end{aligned}
$$



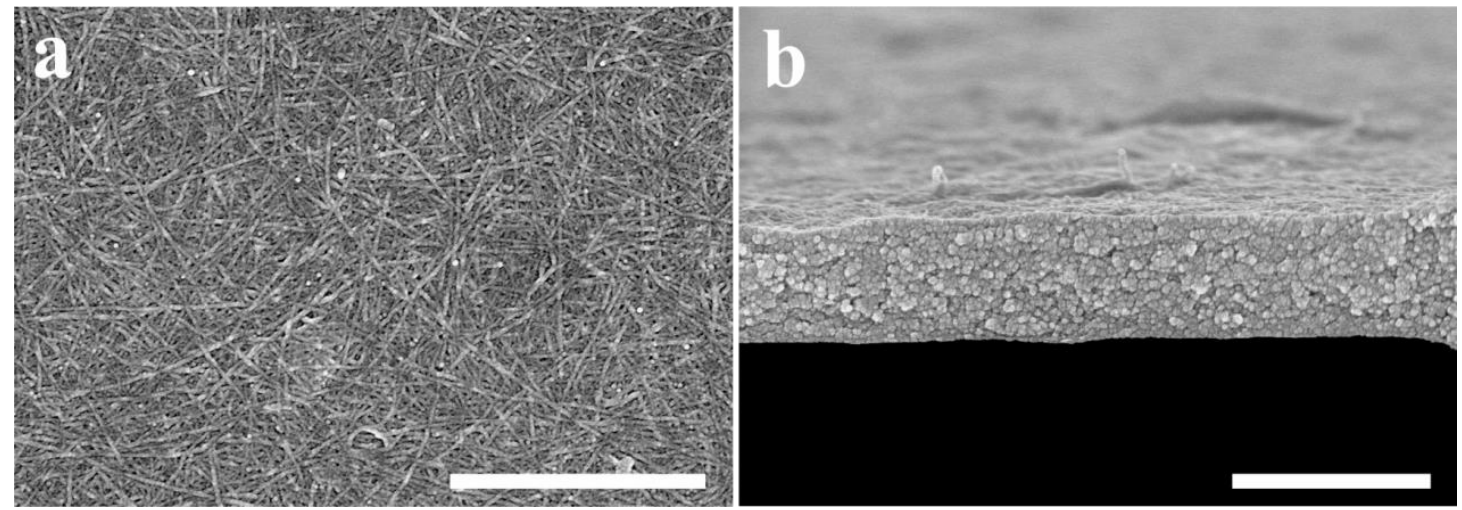

Figure S1. Surface and cross-section SEM images of the copper hydroxide nanostrands thin film precursors. Scare bars were $1 \mu \mathrm{m}$ for (a) and (b).
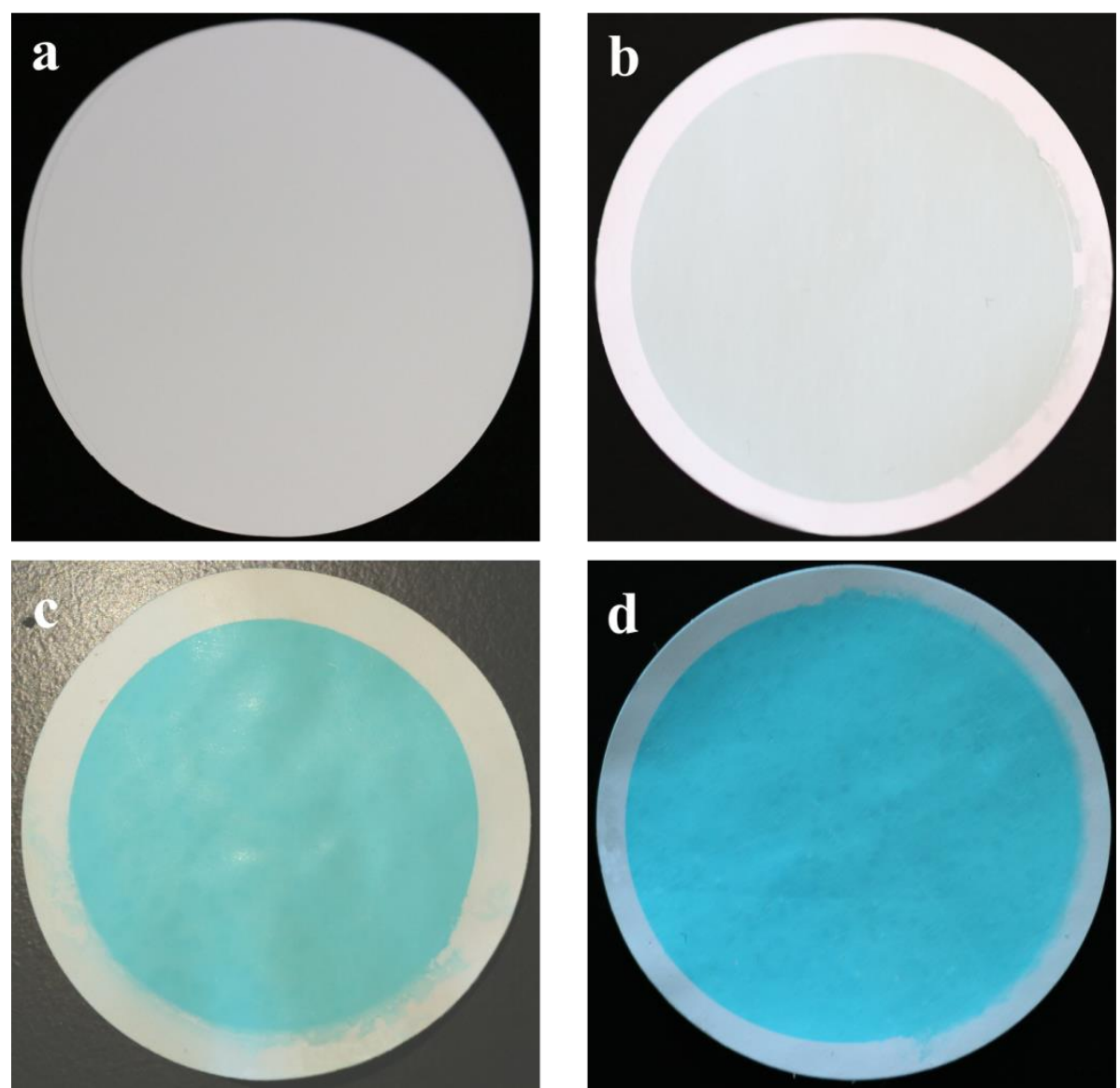

Figure S2. (a) Photographs of bare nylon 66 membrane, (b) copper-hydroxide- nanostrands coated nylon 66 membrane, (c) as-synthesized MOF NAF film coated nylon 66 membrane, (d) as-synthesized MOF bulk film coated nylon 66 membrane. The diameter and pore size of nylon $66 \mathrm{membrane}$ are $47.0 \mathrm{~mm}$ and $0.22 \mu \mathrm{m}$, respectively. 

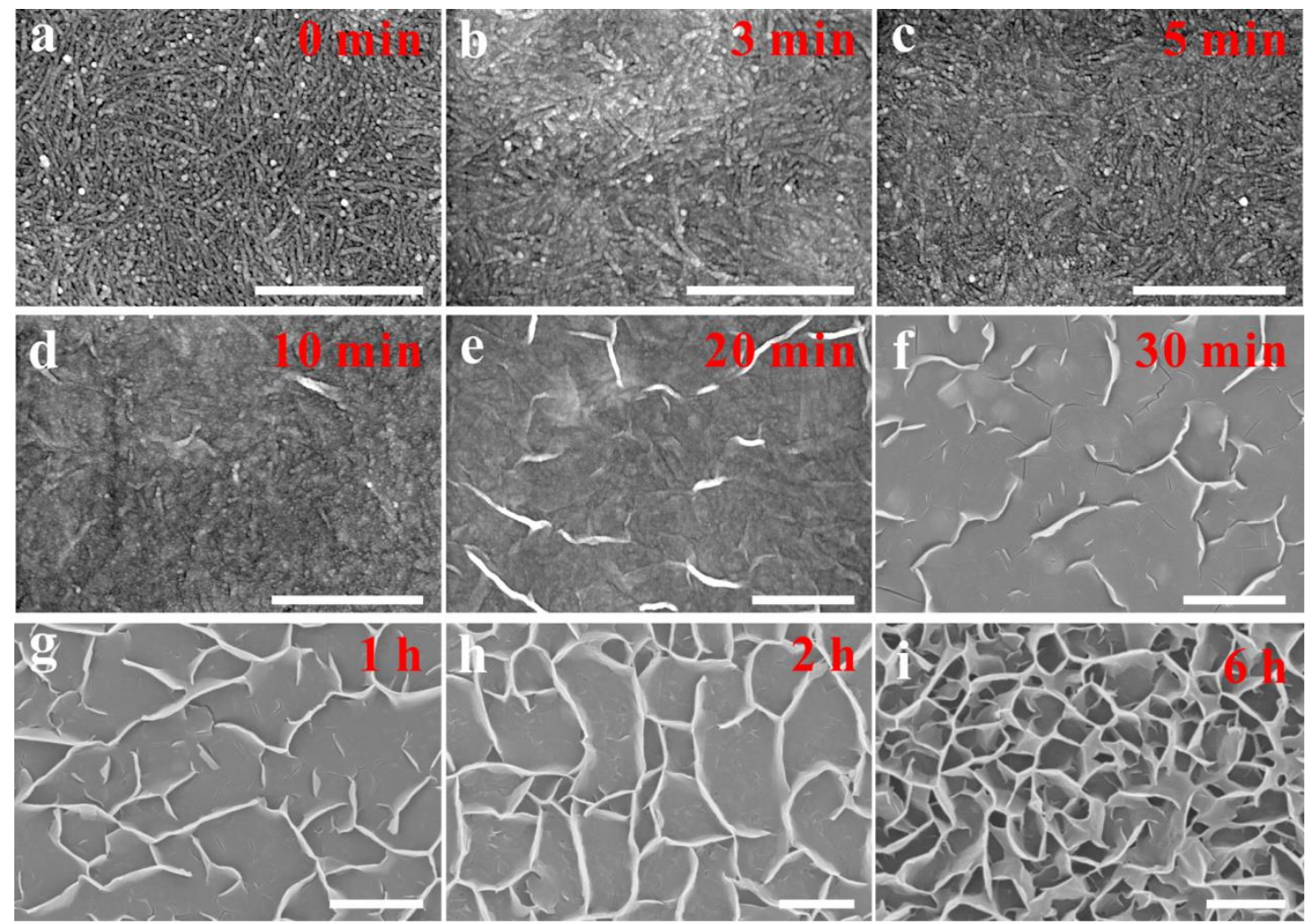

Figure S3. (a-i) Surface SEM images of copper hydroxide nanostrands thin film was transformed into CuBDC NAF at different reaction time (from 0 min to $6 \mathrm{~h}$ ). Scare bars represent $500 \mathrm{~nm}$ for (a-e), $2 \mu \mathrm{m}$ for (f-i).

In the initial time, the surface of copper hydroxide film is quite flat and hundreds of copper hydroxide nanostrands can be see clearly. After dipping into organic ligand solution, the morphology of the parent copper hydroxide nanostrands would readily evolve into blurry. Some small MOFs nanosheet sprout emerged and stacked on the surface of film after $20 \mathrm{~min}$ of reaction at room temperature. When the process was prolonged to $2 \mathrm{~h}$, it was observed that the nanosheets have covered the surface of the film and assembled into frame. The copper hydroxide nanostrands thin film has transformed into nanosheet assembled frame completely at $6 \mathrm{~h}$. 

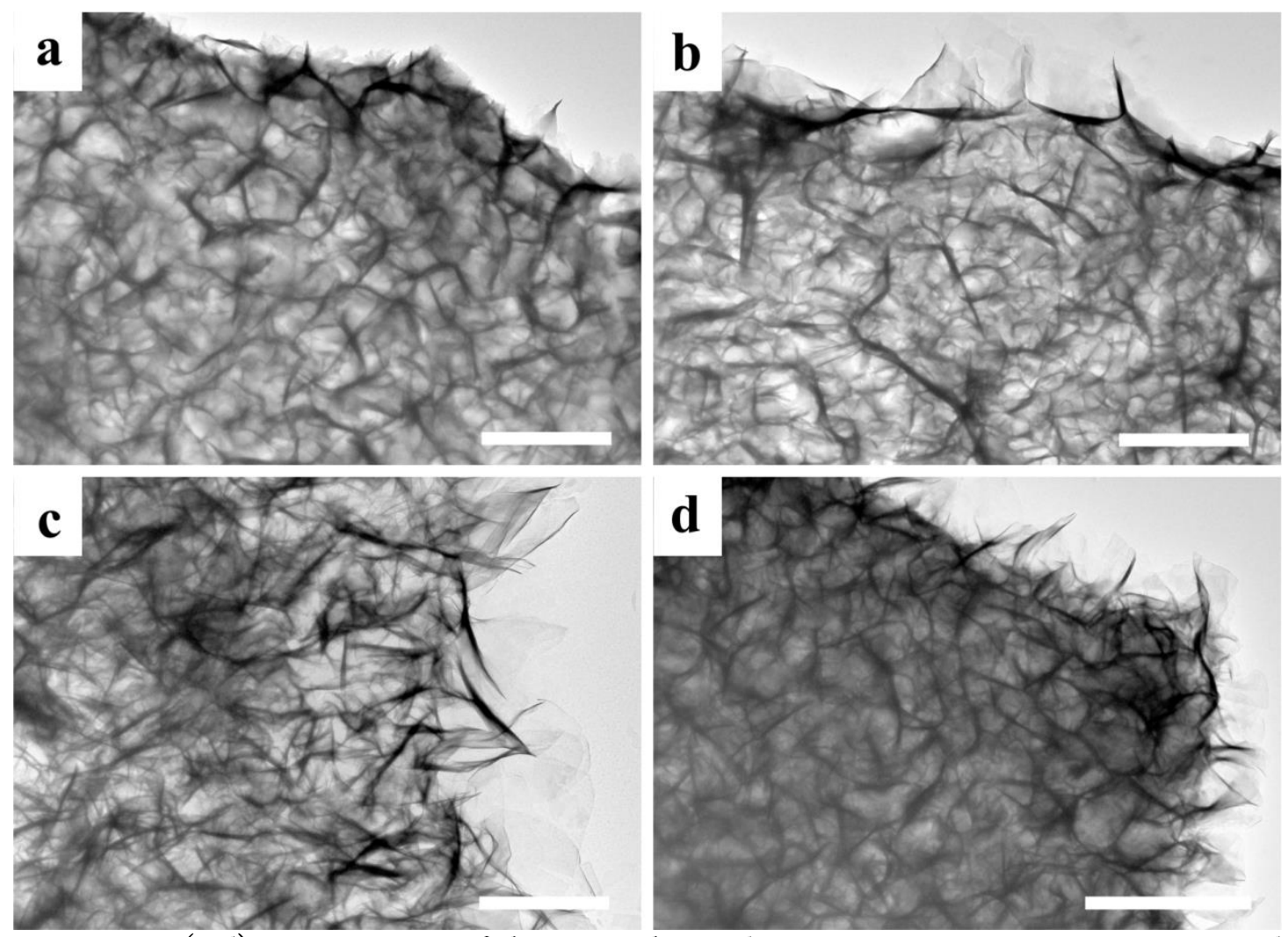

Figure S4. (a-d) TEM images of the as-synthesized MOF NAF-0.5, NAF-1, NAF-2, and NAF-3 products. Scare bars were $2 \mu \mathrm{m}$ for $(\mathrm{a}-\mathrm{c})$ and $5 \mu \mathrm{m}$ for $(\mathrm{d})$. 


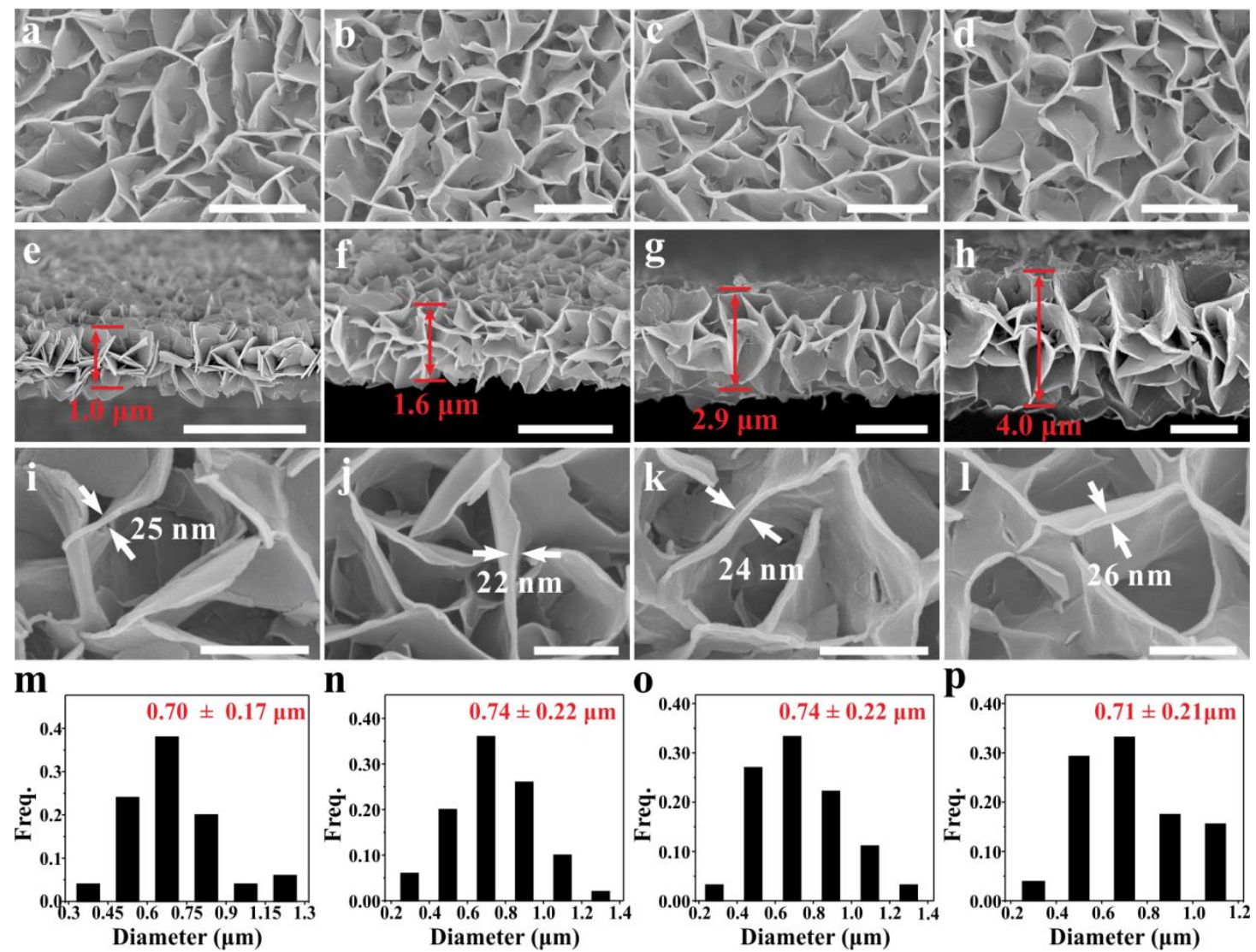

Figure S5. (a, e, i) Surface and cross-section SEM images of the NAF-0.5 film, (b, f, j) Surface and cross-section SEM images of the NAF-1 film, (c, g, k) Surface and cross-section SEM images of the NAF-2 film, (d, h, l) Surface and cross-section SEM images of the NAF-3 film. Scare bars were $1 \mu \mathrm{m}$ for $(\mathrm{a}-\mathrm{d}), 2 \mu \mathrm{m}$ for $(\mathrm{e}-\mathrm{h})$ and $500 \mathrm{~nm}$ for $(\mathrm{i}-1)$. $(\mathrm{m}-\mathrm{p})$ The size distributions of the macropores of the NAF-0.5, NAF-1, NAF-2 and NAF-3 films.

\section{MOFs NAF film}

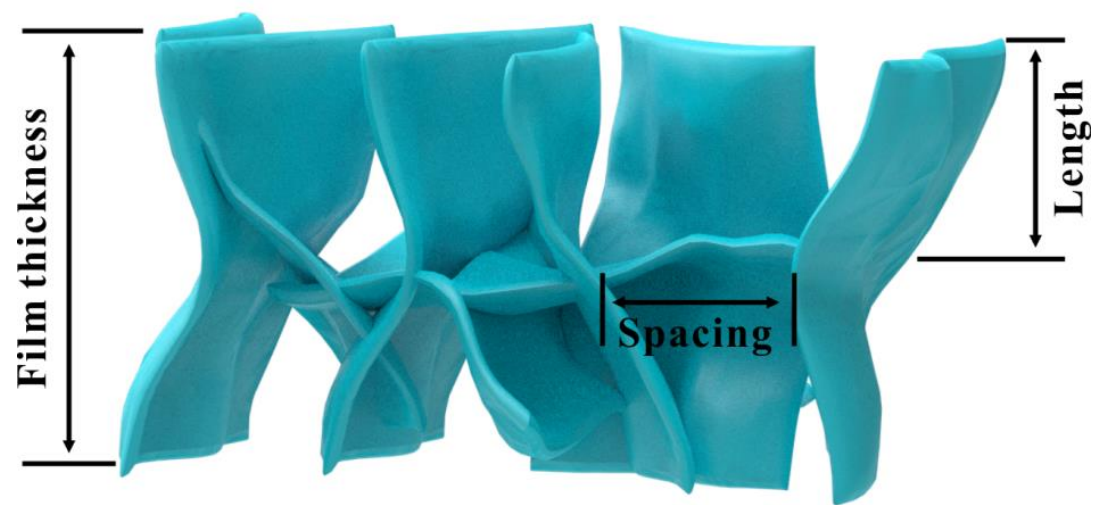

Figure S6. Schematic diagram of the calculation of length-to-spacing ratio.

From the Figure $S 4 m-4 p$, statistical analysis of size distributions reveals that the four NAF films have similar macropores with size $\sim 0.74 \mu \mathrm{m}$. So the spacing between two nanosheets is set as $0.74 \mu \mathrm{m}$. As the NAF films with thicknesses of $\sim 1.0, \sim 1.6, \sim 2.9$ and $\sim 4.0 \mu \mathrm{m}$, so the length of the nanosheets is determined to be about $0.5,0.8,1.45$ and $2.0 \mu \mathrm{m}$. After approximate treatment, the length-to-spacing ratio of the NAF films is set as $0.5,1,2$ and 3 . 

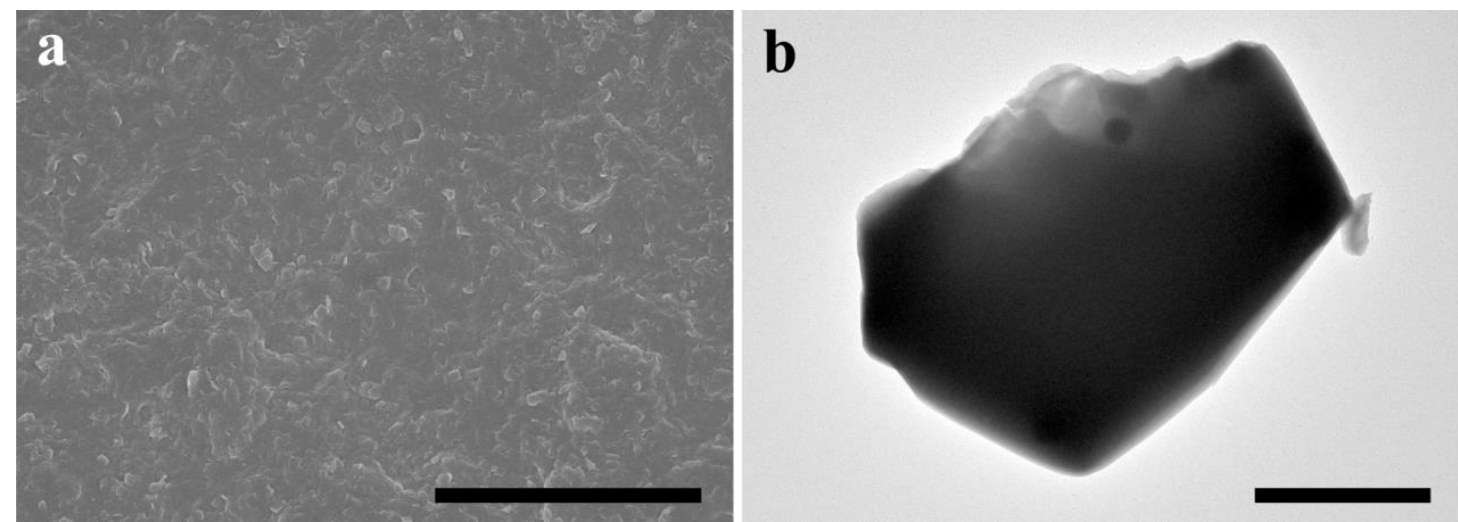

Figure S7. Surface SEM image and TEM image of the MOF film. Scare bars were $5 \mu \mathrm{m}$ for (a) and (b).

$\mathbf{a}$
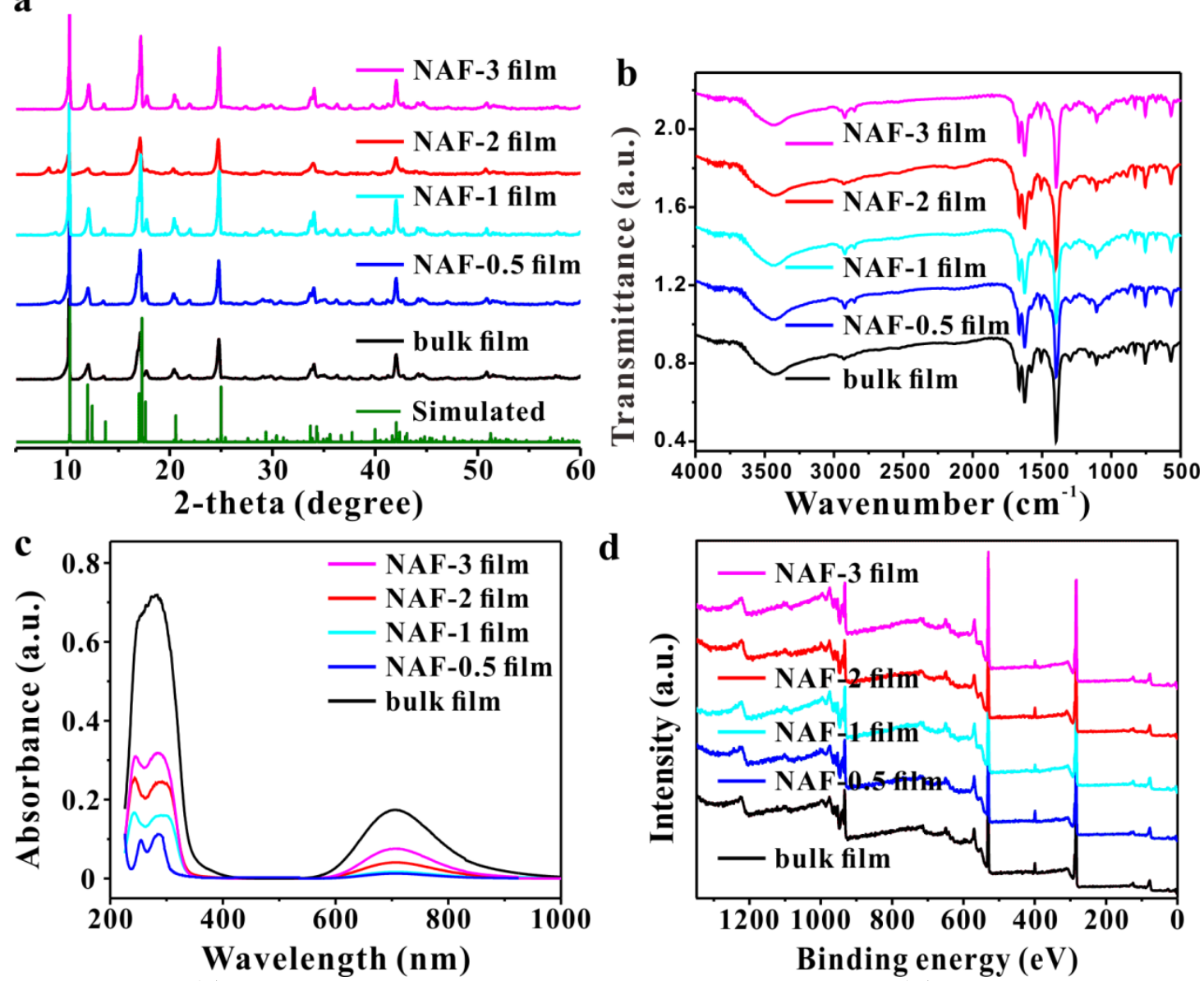

Figure S8. (a) XRD patterns of as-synthesized MOF films, (b) FT-IR spectra of as-synthesized MOF films, (c) Ultraviolet-visible diffuse reflectance spectra of as-synthesized MOF films, (d) XPS patterns of as-synthesized MOF films.

As the MOFs nanosheets in this research are $\sim 25 \mathrm{~nm}$ thick, the XRD patterns of nanosheets are more similar to bulk-type MOFs rather than ultrathin nanosheet. Herein, the intensity of $\mathrm{XRD}$ patterns is relative intensity. After normalization, the XRD patterns of the MOF NAF film are supposed to be similar to that of bulk-type MOF film. 


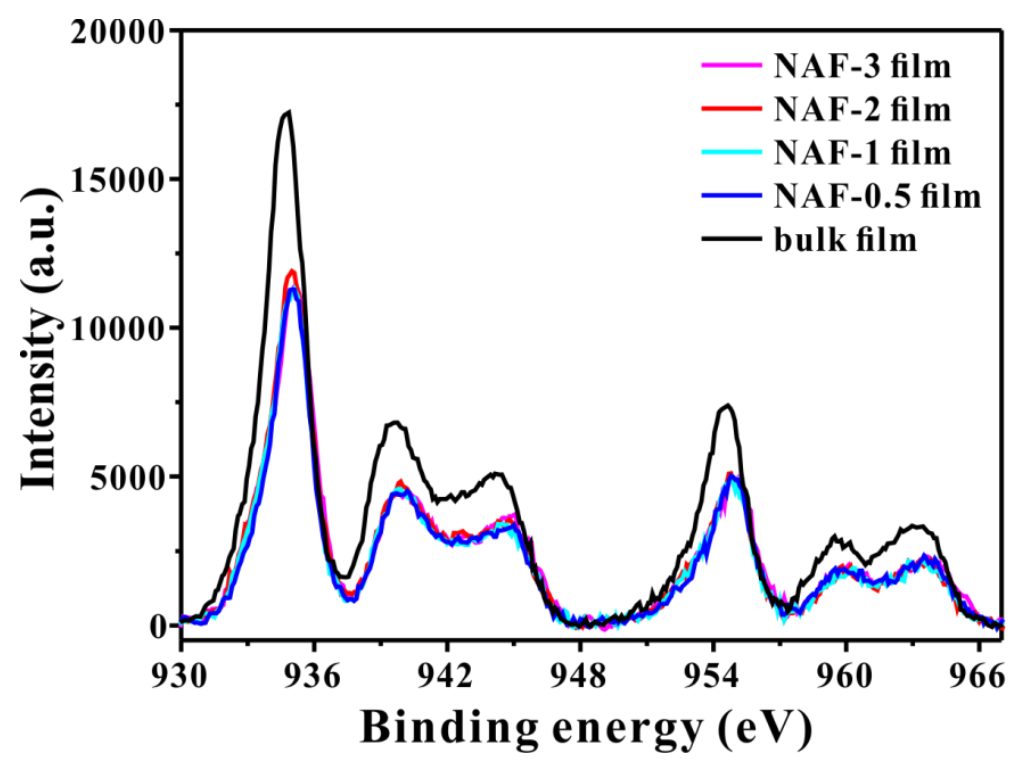

Figure S9. High-resolution XPS spectra of $\mathrm{Cu} 2 \mathrm{p}$ of as-synthesized MOF films.

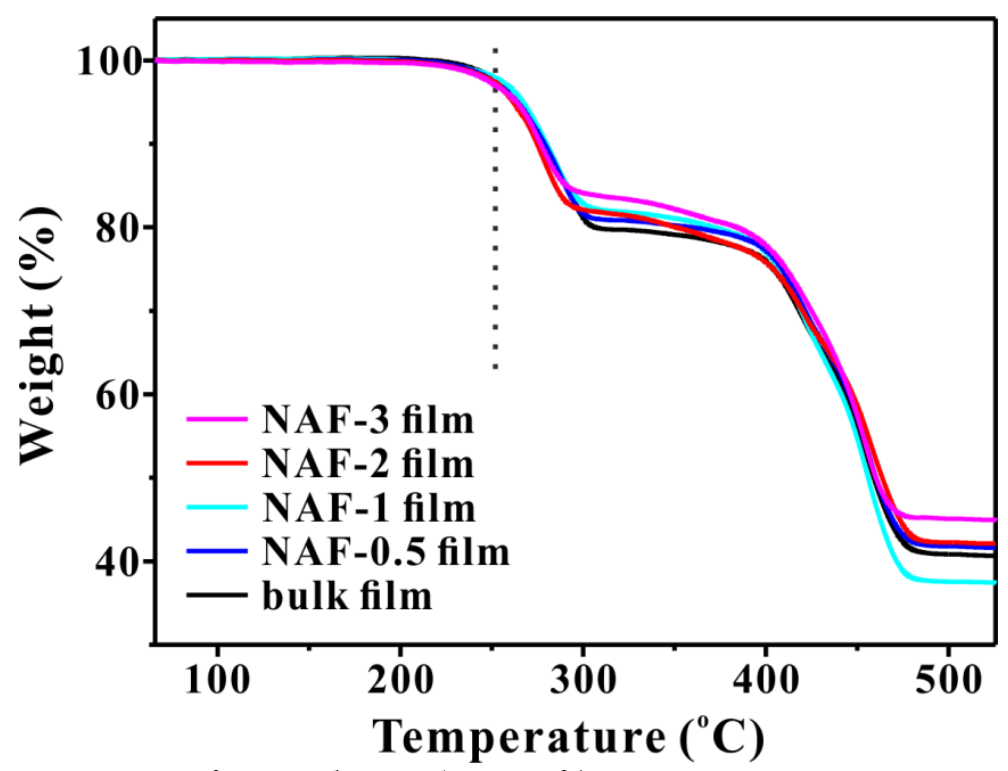

Figure S10. TGA curves of as-synthesized MOF films.

The difference in weight loss of MOFs films is caused by the experimental random errors. As shown in TGA curves, the weight loss of bulk-type MOF, NAF-0.5, NAF-1, NAF-2 and NAF-3 are $59.8 \%, 58.8 \%, 62.6 \%, 58.5 \%$ and $55.7 \%$, respectively. Their average weight loss is $59.1 \%$ with $2.5 \%$ standard deviation. The coefficient of variation estimates to be 4.2 , which is common in preparation and application of MOFs nanomaterials. 


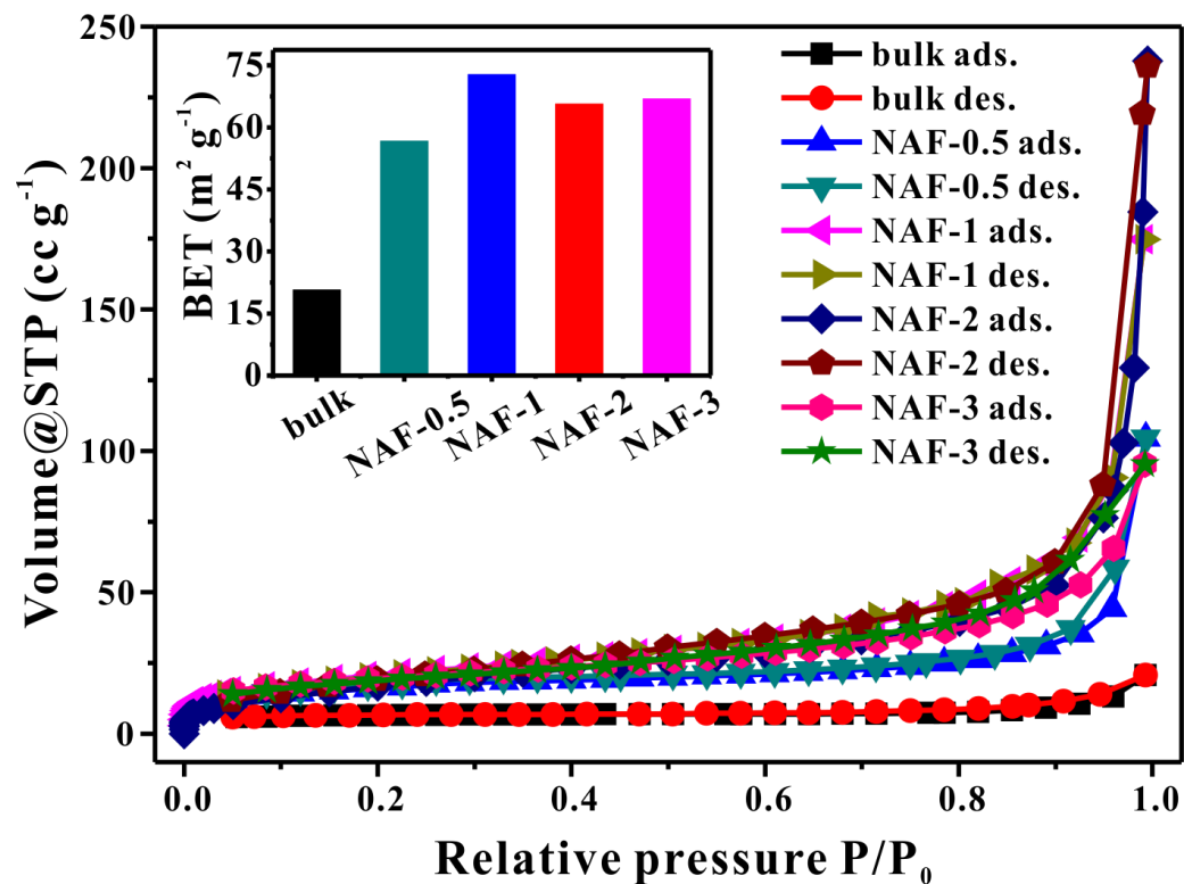

Figure S11. Nitrogen adsorption and desorption isotherms measured at $77 \mathrm{~K}$ of as-synthesized bulk, NAF-0.5, NAF-1, NAF-2 and NAF-3 films. The inset shows $S_{\mathrm{BET}}$ for five MOF films.

The difference in BET surface area of MOFs films is caused by the experimental random errors. The BET surface area of NAF-0.5, NAF-1, NAF-2 and NAF-3 are 56.9, 72.9, 65.8 and $67.0 \mathrm{~m}^{2} \mathrm{~g}^{-1}$, respectively. Their mean value is $65.7 \mathrm{~m}^{2} \mathrm{~g}^{-1}$ with $6.6 \mathrm{~m}^{2} \mathrm{~g}^{-1}$ standard deviation. BET surface area of MOF adopts 10 inter-assay coefficient of variation.

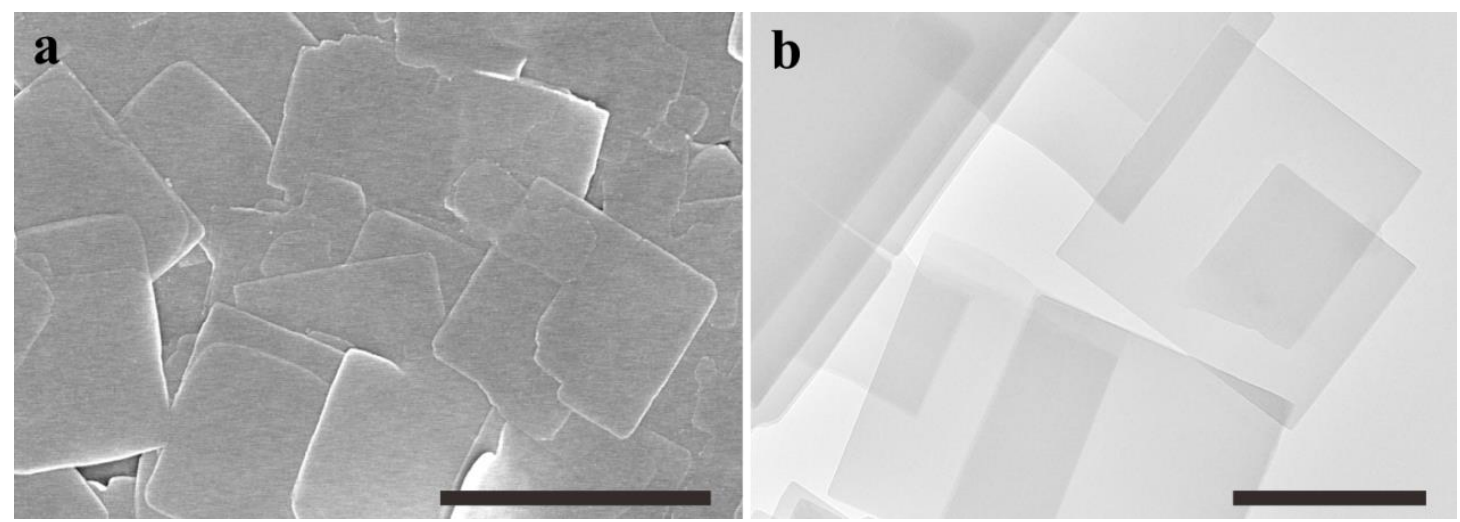

Figure S12. (a) The surface SEM image of the nanosheets for the test film samples on $\mathrm{Si} / \mathrm{SiO}_{2}$ substrates. (b) The TEM for the nanosheets. Scale bars represent $2 \mu \mathrm{m}$ for (a) and 1 $\mu \mathrm{m}$ for (b).

Here, the 2D MOF nanosheet films can be prepared on solid substrates by using the Langmuir-Schäfer method., ${ }^{2,3}$ 


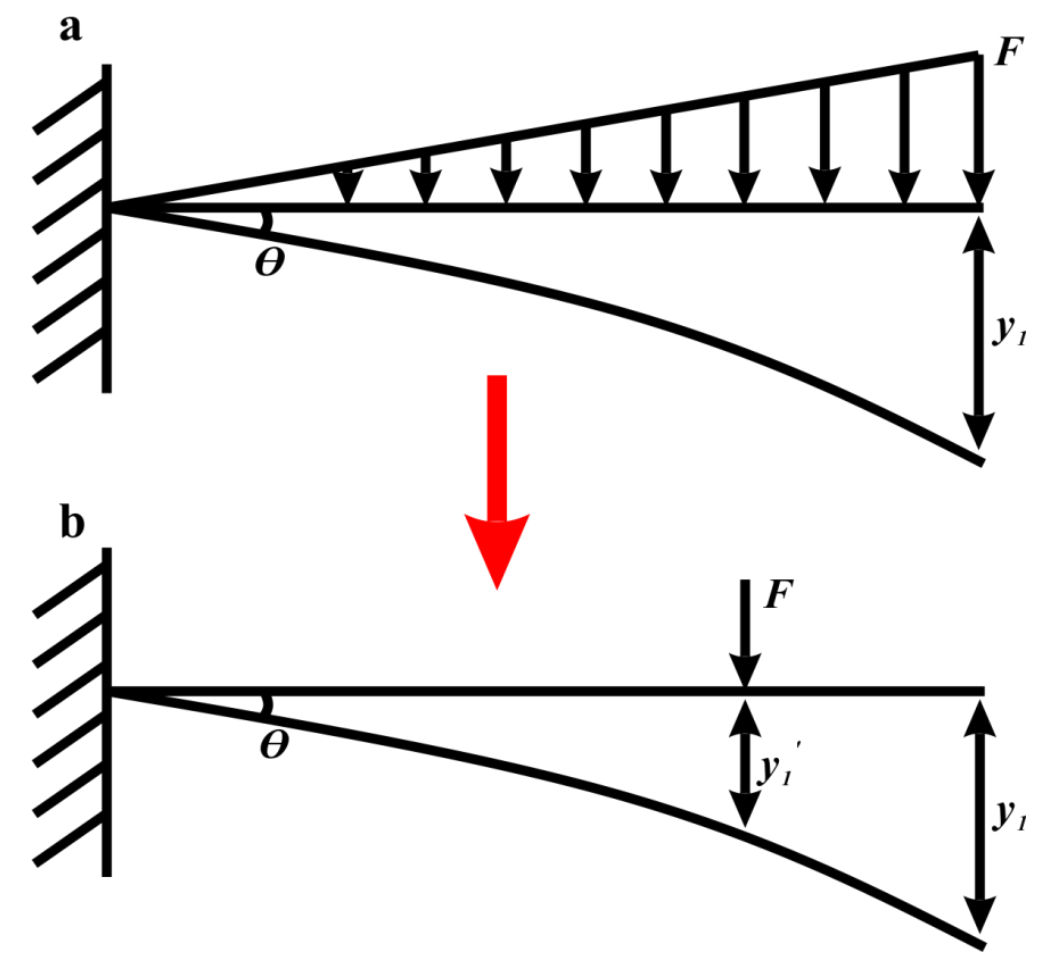

Figure S13. (a) Distributed load in the flow field acting on the nanosheets. (b) Distributed load simplified to concentrated load.

The effect of the upper and lower loads is the same.

a

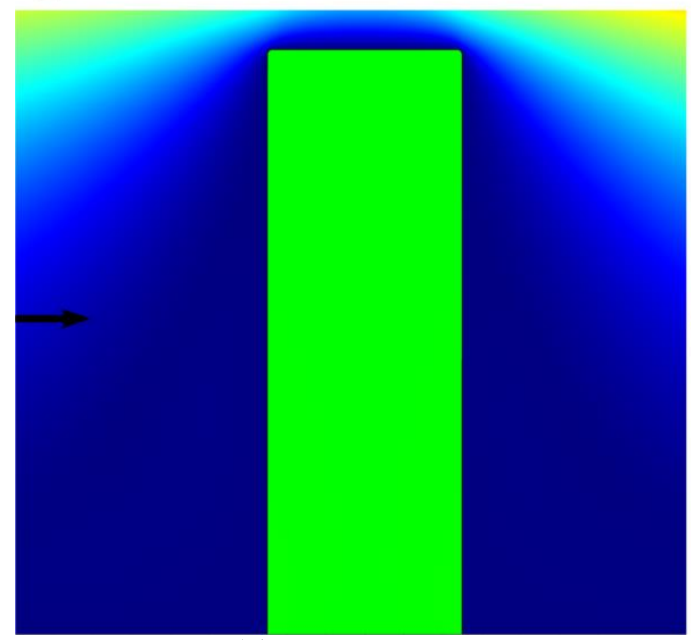

b

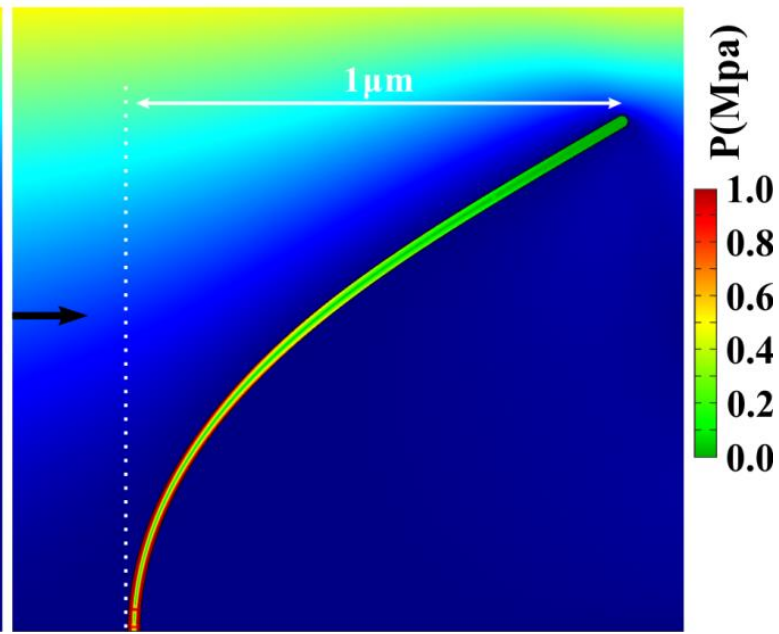

Figure S14. (a) The magnified region of flow distribution illustrates that the von Mises stresses concentrate at the bottom of the bulk. (b) The magnified region of flow distribution illustrates that the von Mises stresses concentrate at the bottom of a single MOF nanosheet. The arrow indicates the flow direction. 

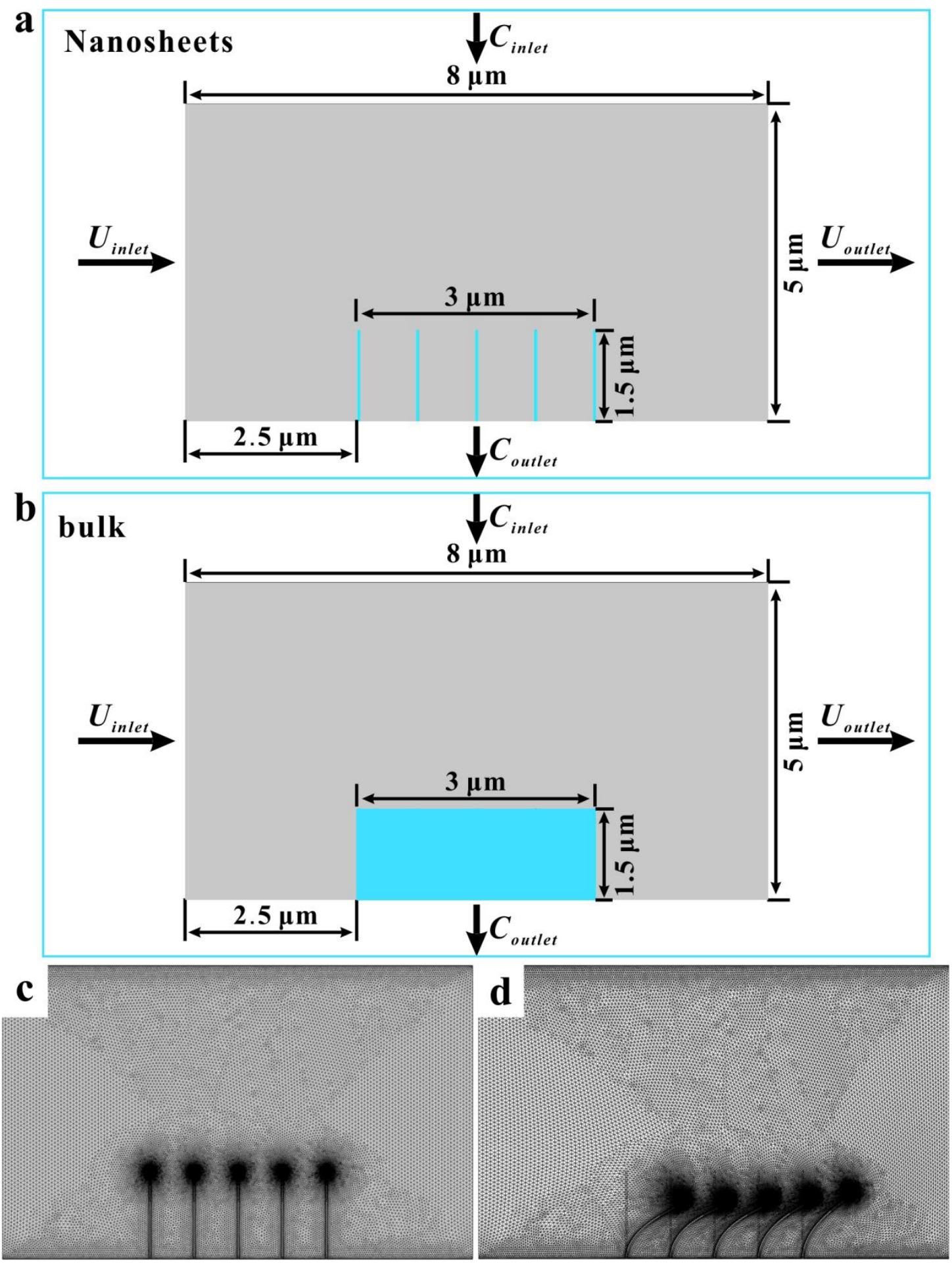

Figure S15. (a, b) Simulation setup. The spacing of the nanosheets is $750 \mathrm{~nm}$. (c) Initial grids, (d) Remeshed grid during motion.

The left boundary of the channel is set as the inlet boundary while the right boundary as the exit boundary condition. For transport of reaction component, the top wall of channel is set as the concentration inlet boundary. 


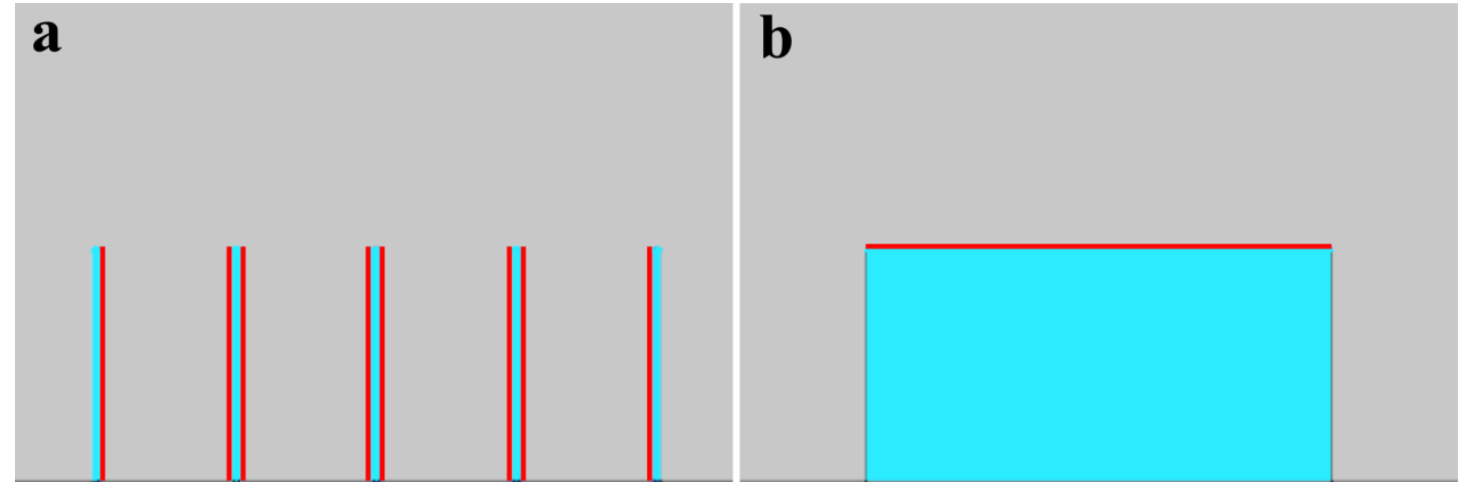

Figure S16. Nanosheets/bulk faces used to integrate the mass of the reactants in the simulation. a) nanosheets, b) bulk.

To quantify the efficiency of mass transport and thus reaction, here we estimate the amount of the reactant delivered to the reaction surface, i.e., the surfaces of nanosheets denoted by red lines. As shown in Figure S16, the concentration at the surfaces of the nanosheets/bulk marked in red in the figure is integrated to obtain the mass of the reactants that the nanosheet/body film can contact. The more the mass of the reactants can be transported to the reaction sites, the higher the reaction is. 


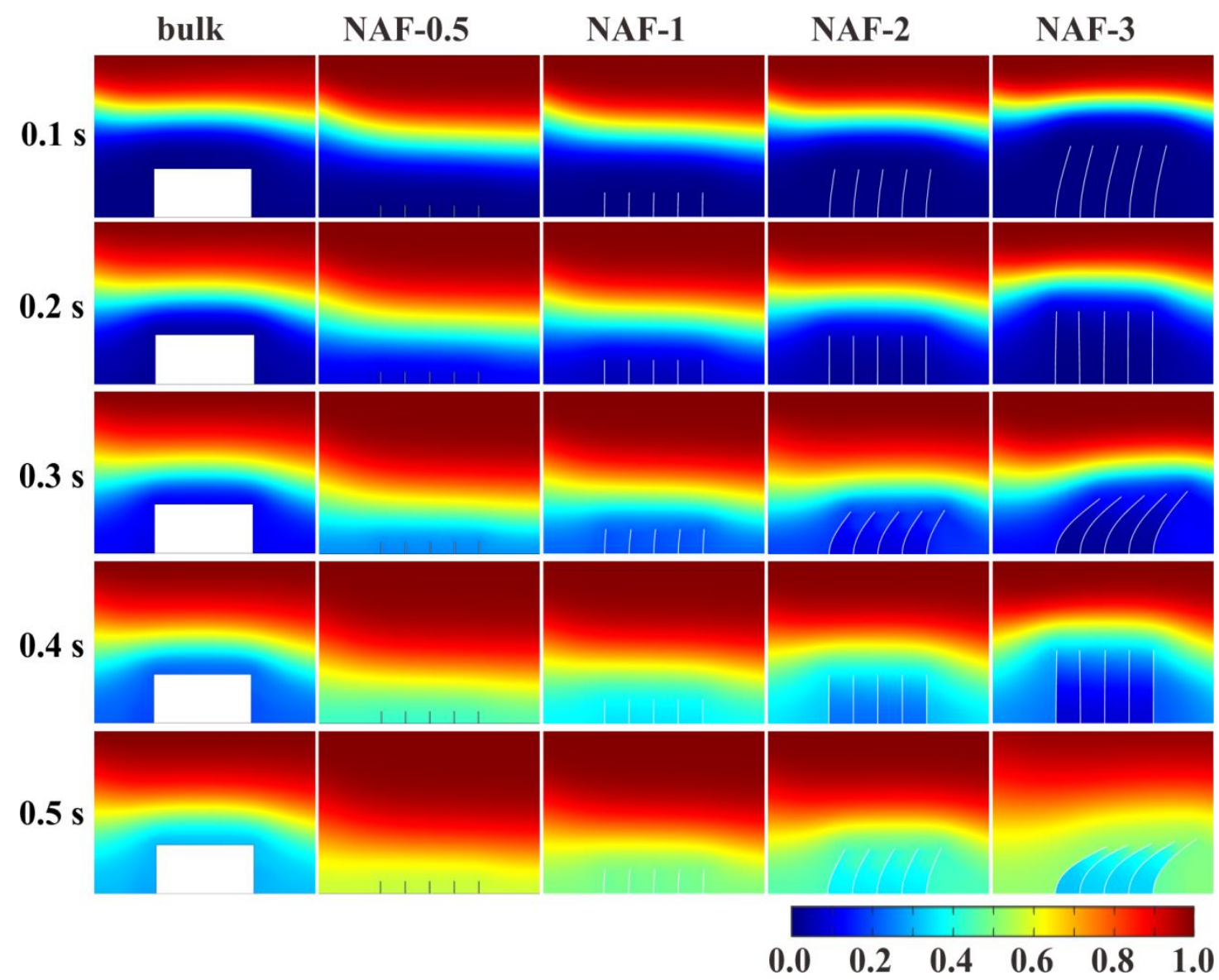

Figure S17. The diagram of concentration field of bulk, NAF-0.5, NAF-1, NAF-2 and NAF-3 films at different time.

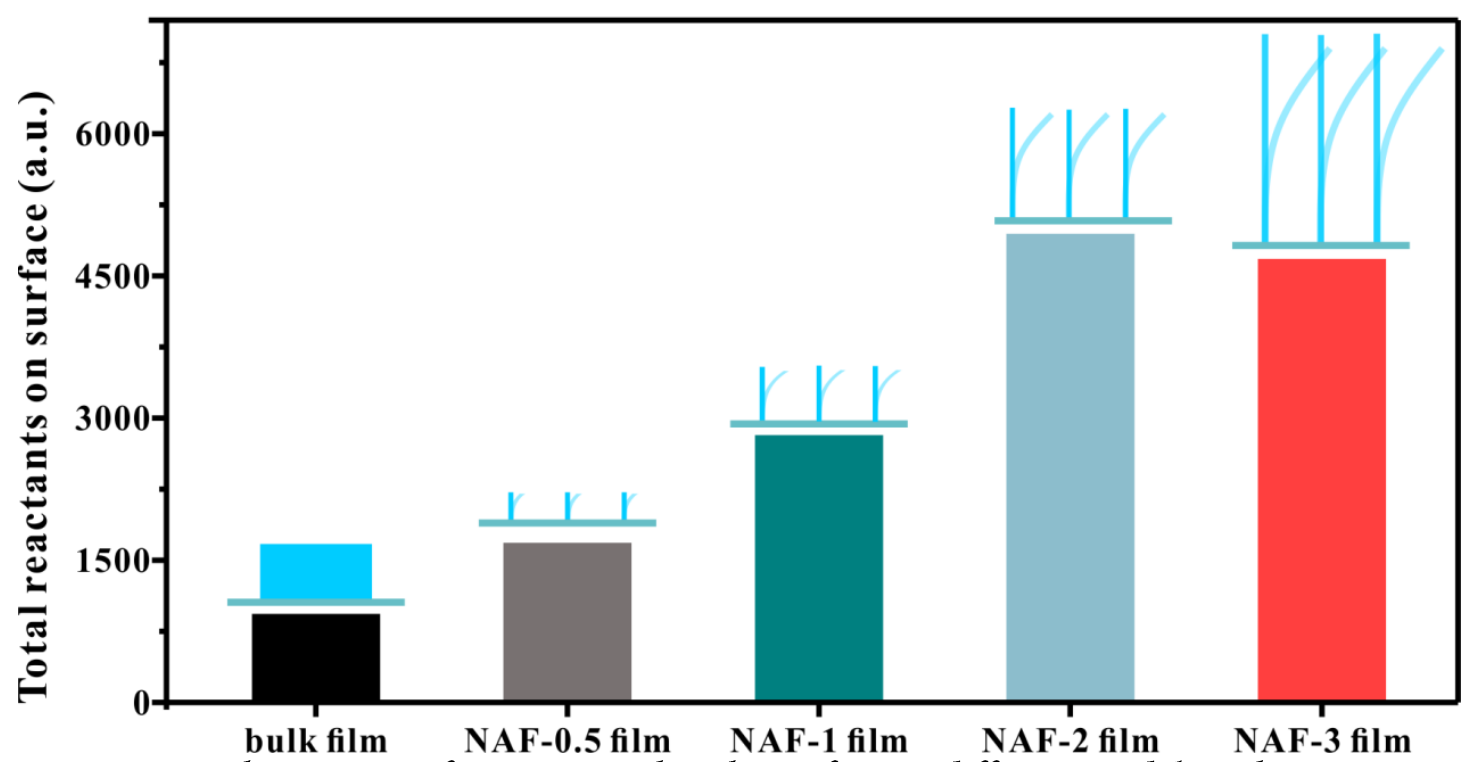

Figure S18. The amount of reactant reaches the surface on different models at the same time obtained from numerical simulations. 

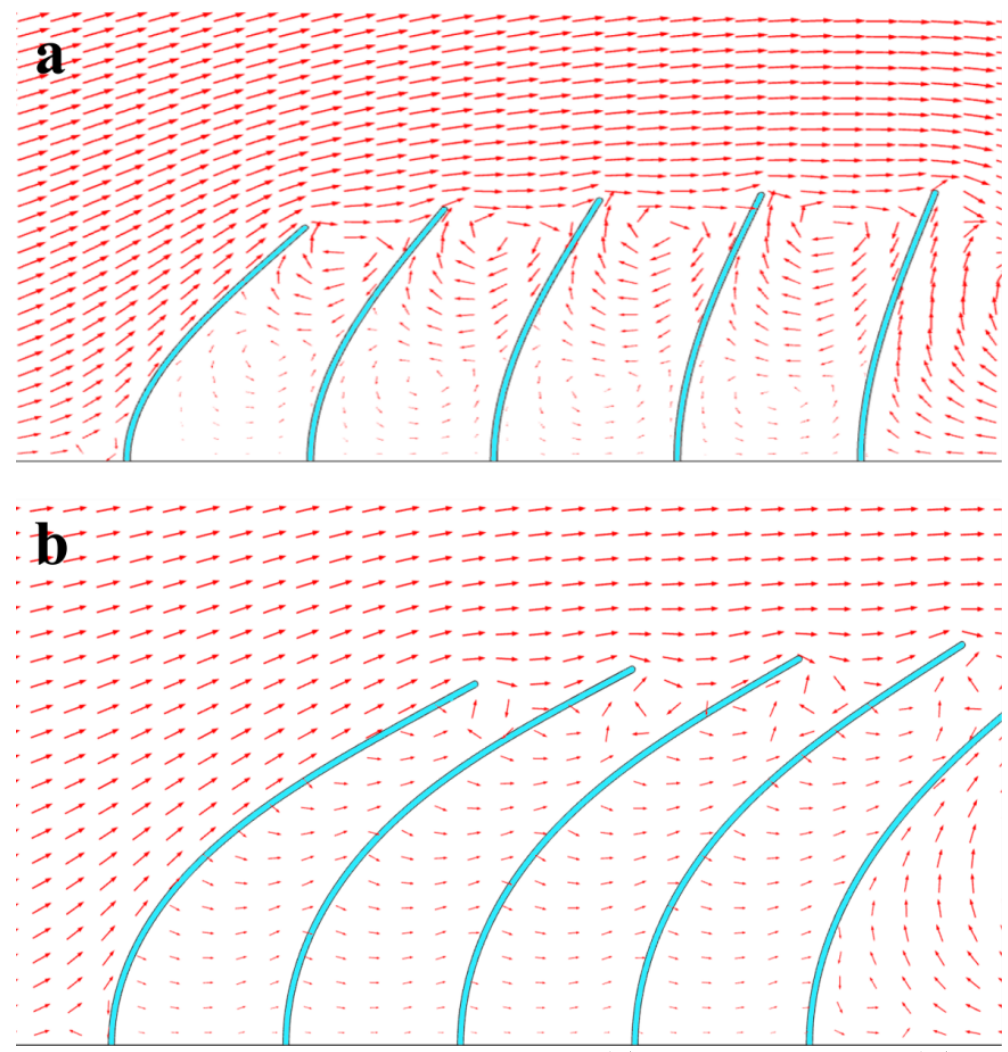

Figure S19. The vortices generated by the NAF-2 (a) and the NAF-3 (b) in the flow field. Strong vortices can be generated by the swing of the NFA- 2 while the vortices generated by the NFA-3 become weak.

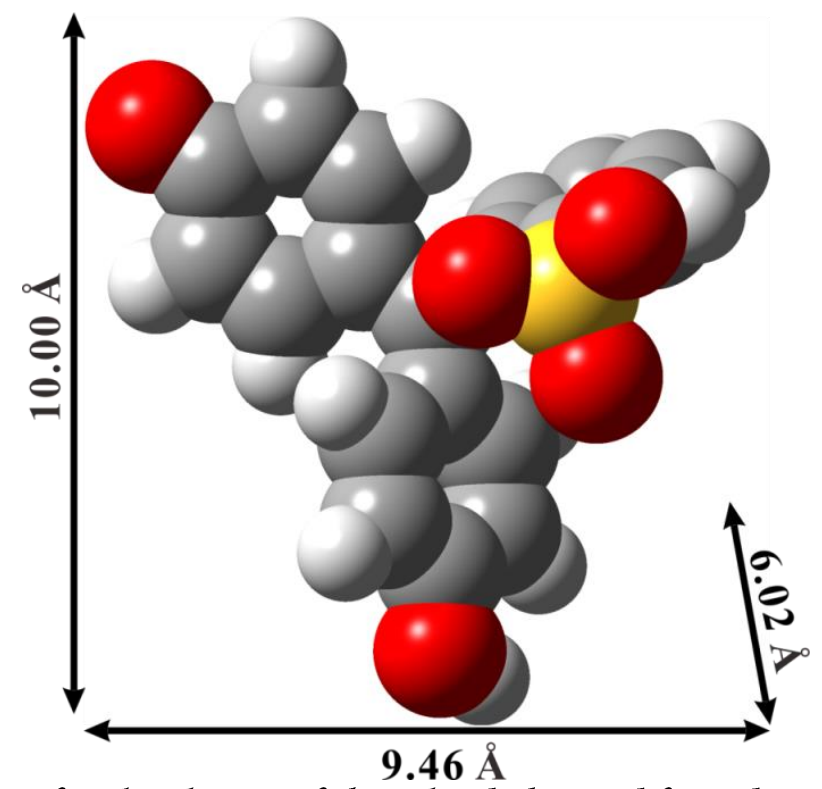

Figure S20. Scheme of molecule size of phenol red obtained from density functional theory (DFT), the DFT calculation was made in ethanol solvent on a B3LYP/6-31 + G(d) level with GAUSSIAN 09 software package. ${ }^{4}$ 


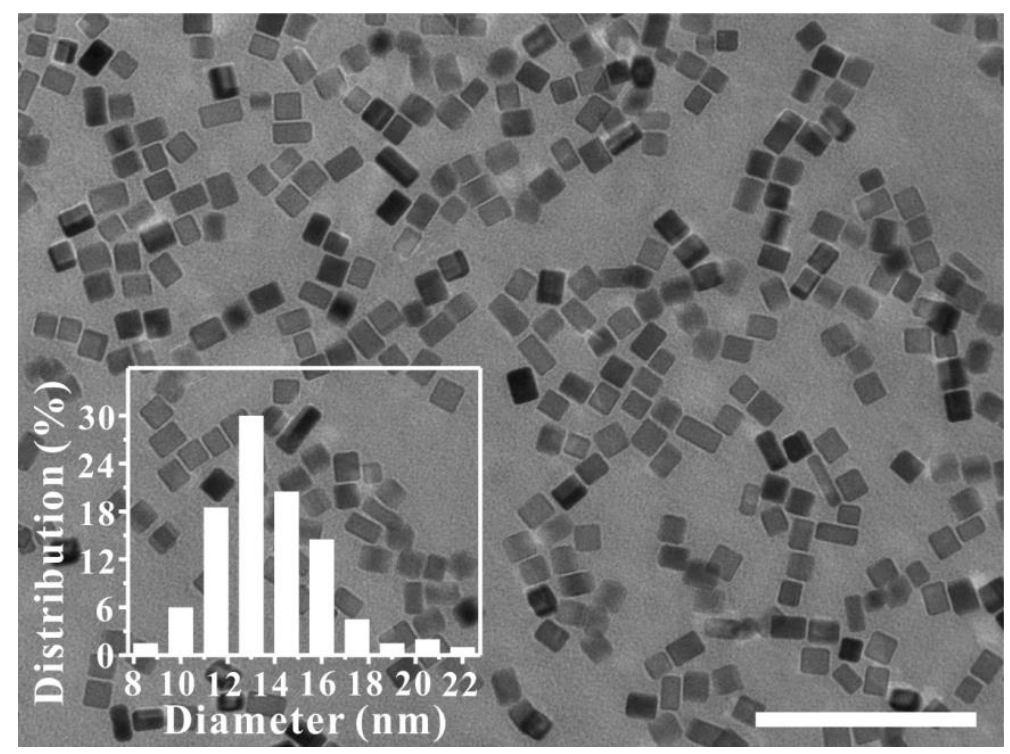

Figure S21. TEM image of Pd NCs, the inset image shows a size distribution for as-synthesized Pd NCs. Scare bar is $100 \mathrm{~nm}$.

Transmission electron microscopy (TEM) study suggests that the Pd NCs have a well-defined structure with sizes of $15.4 \pm 1.5 \mathrm{~nm}$.
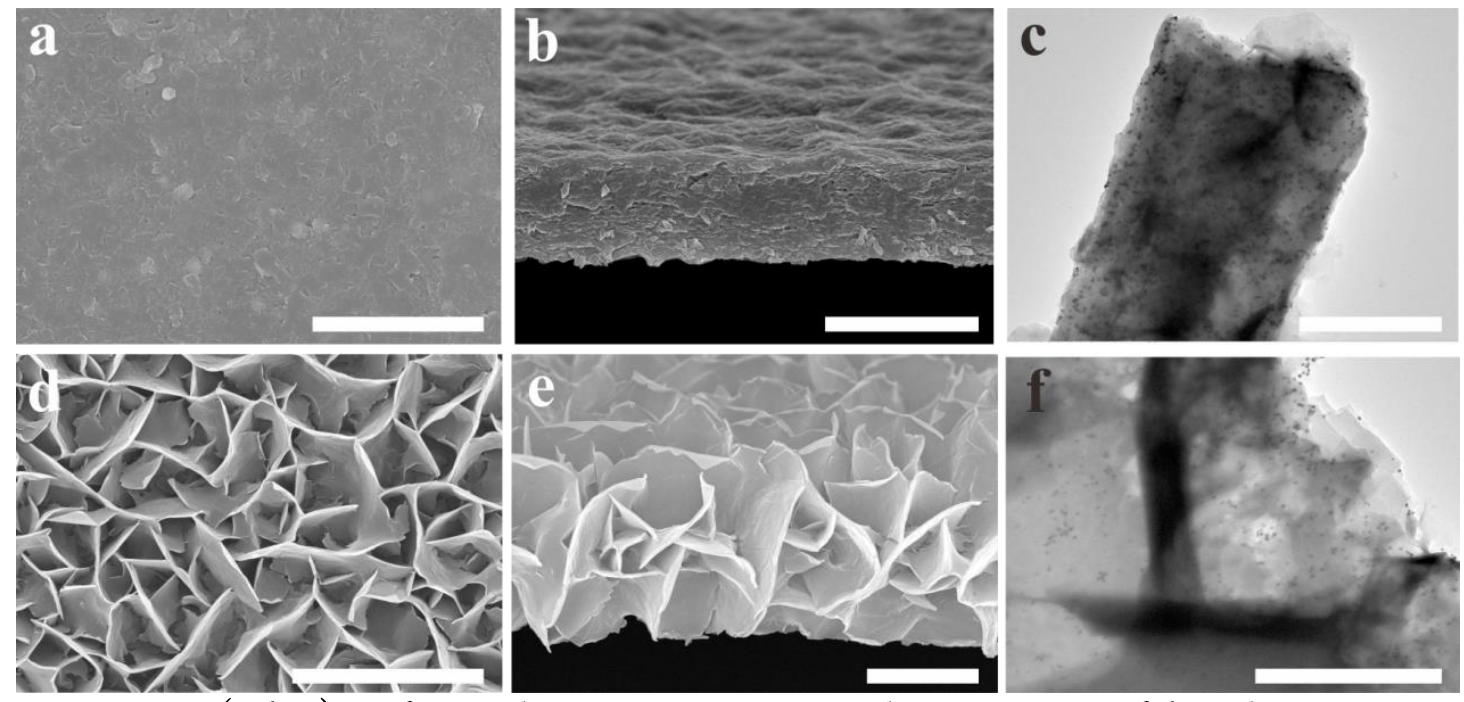

Figure S22. (a, b, c) Surface and cross-section SEM and TEM images of the Pd NCs@MOF bulk film prepared with high concentration of organic ligand; (d, e, f) Surface and cross-section SEM and TEM images of the Pd NCs@NAF-2 prepared with low and high concentration of organic ligand. Scare bars were $5 \mu \mathrm{m}$ for (a) and (d), $2 \mu \mathrm{m}$ for (b, e), and 1 $\mu \mathrm{m}$ for $(c, f)$. 

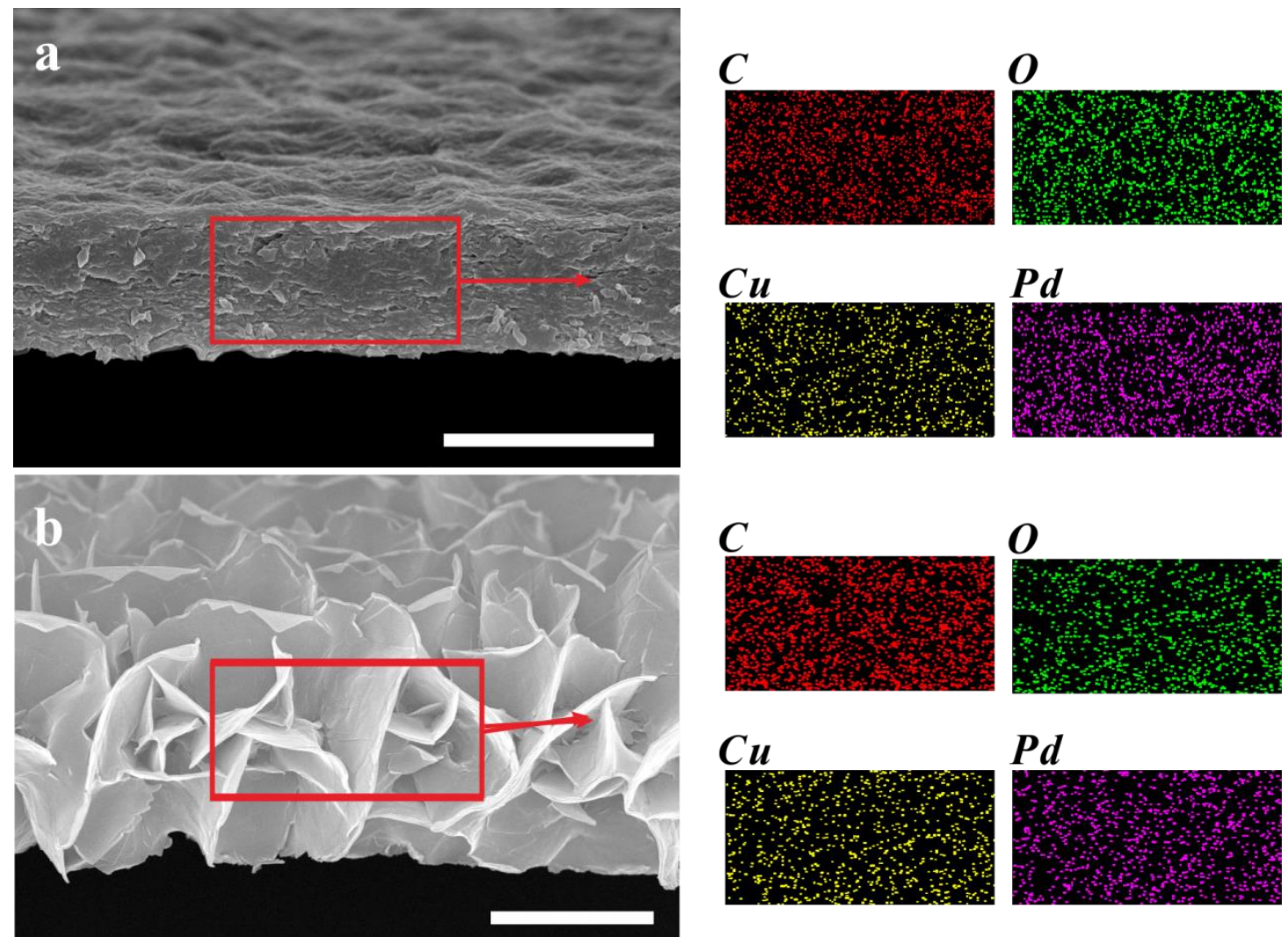

Figure S23. (a, b) cross-section SEM images of the Pd NCs@bulk film and Pd NCs@NAF-2 film composites prepared with two different concentrations of organic ligand and and their corresponding energy dispersive X-ray elemental mapping results. Scare bars were $2 \mu \mathrm{m}$ for $(\mathrm{a}, \mathrm{b})$.

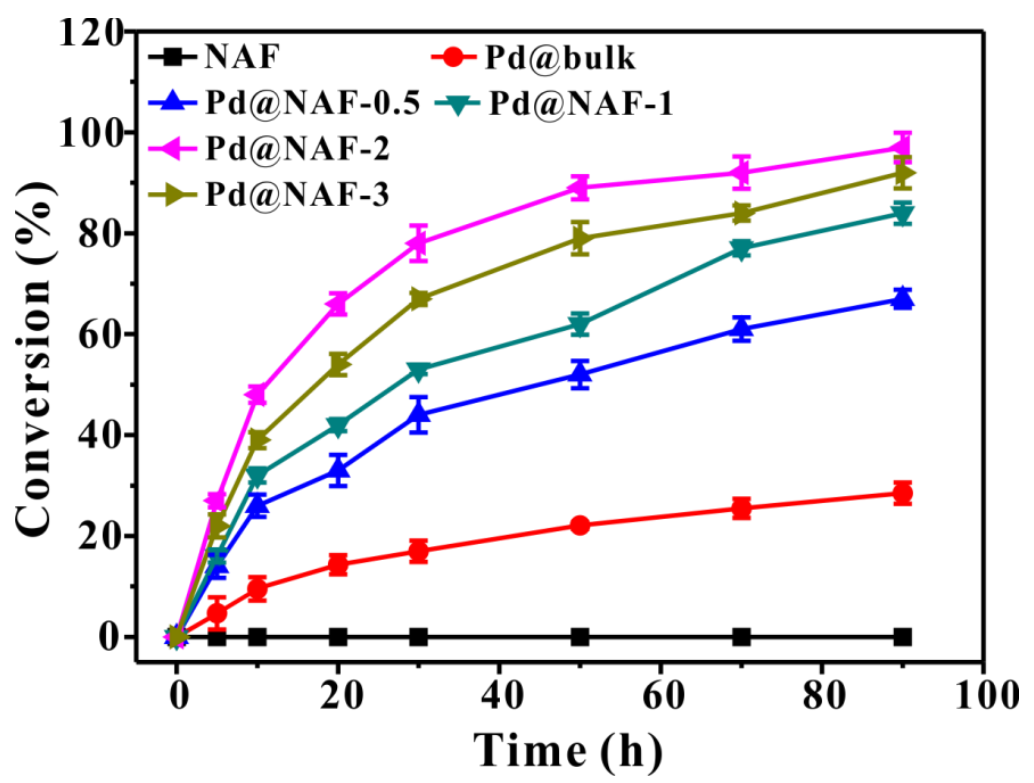

Figure S24. Dependence of the hydrogenation yield of 1-hexene on the reaction time over MOF, Pd NCs@bulk and Pd NCs@NAF films. 


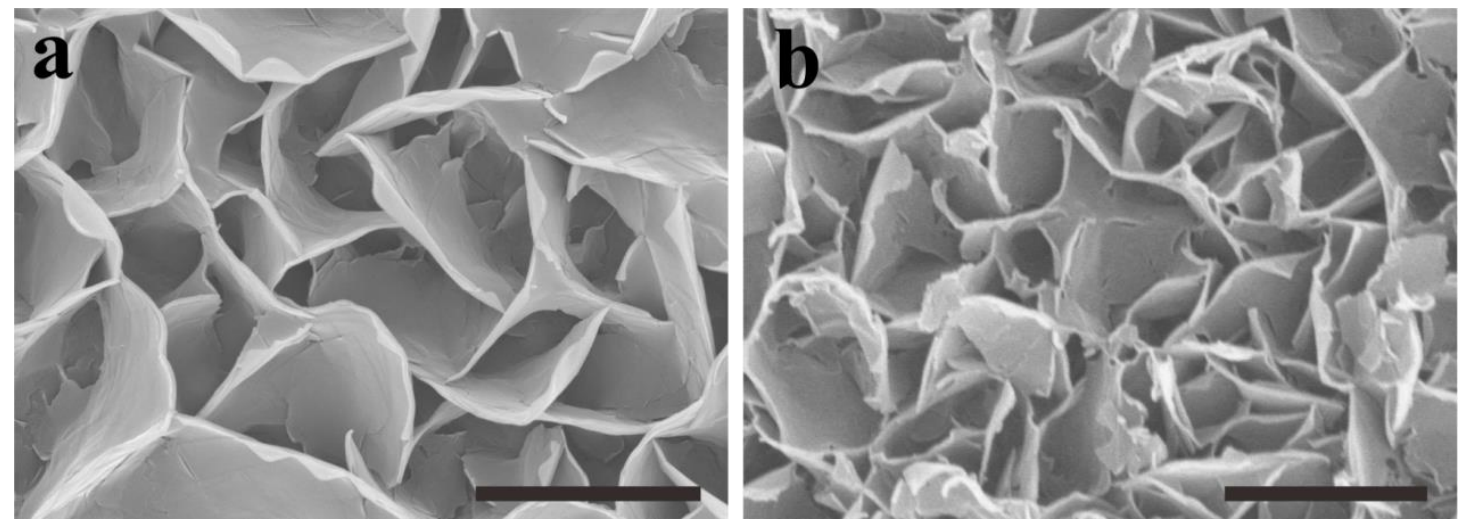

Figure S25. (a) Surface SEM image for as-synthesized Pd NCs@NAF-2 film. (b) Surface SEM image for Pd NCs@NAF-2 film after 3 consecutive runs of reaction. Scare bars were 2 $\mu \mathrm{m}$ for $(\mathrm{a}-\mathrm{b})$.

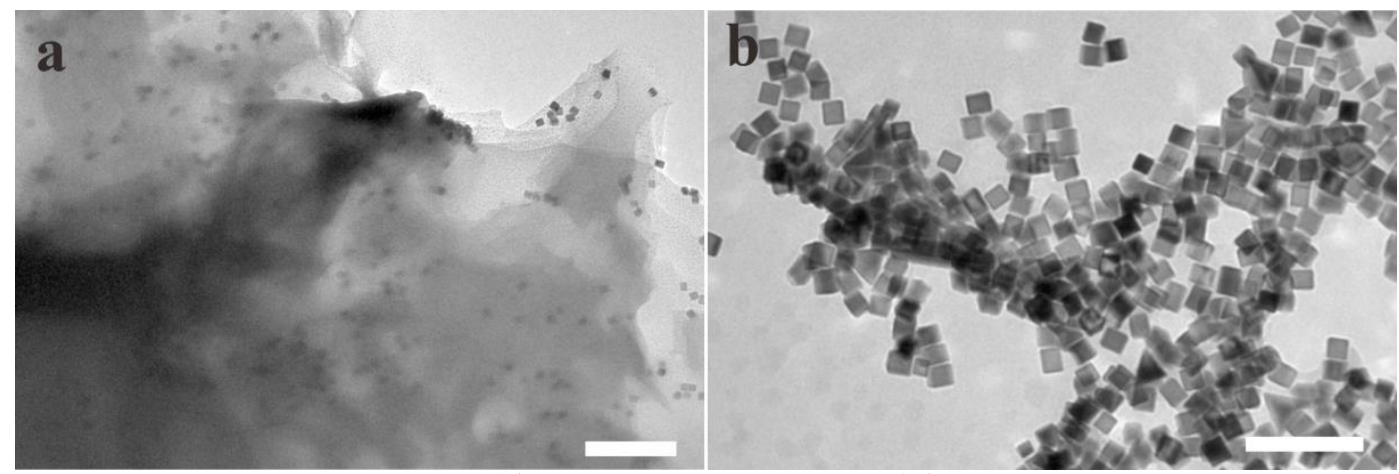

Figure S26. TEM images for (a) Pd NCs@NAF-2 and (b) Pd NCs after 3 consecutive runs of reaction. Scare bars were $200 \mathrm{~nm}$ for (a), and $100 \mathrm{~nm}$ for (b). 


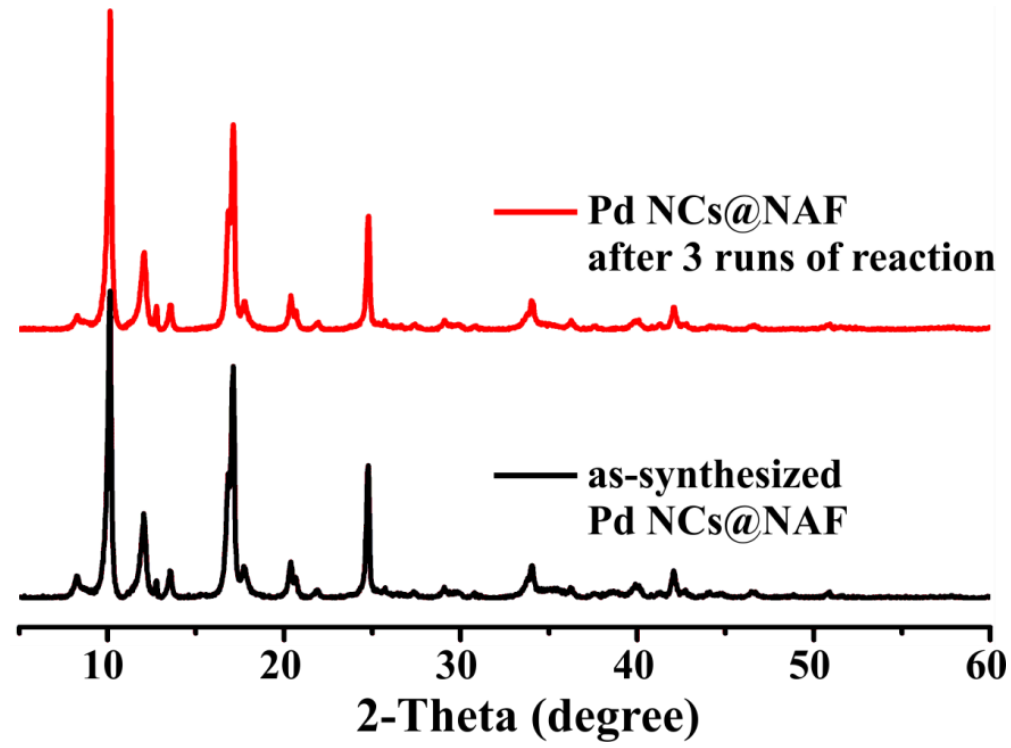

Figure S27. Powder XRD patterns for as-synthesized Pd NCs@NAF-2 and experimental Pd NCs@NAF-2 composites after 3 cycles of hydrogenation of 1-hexene.

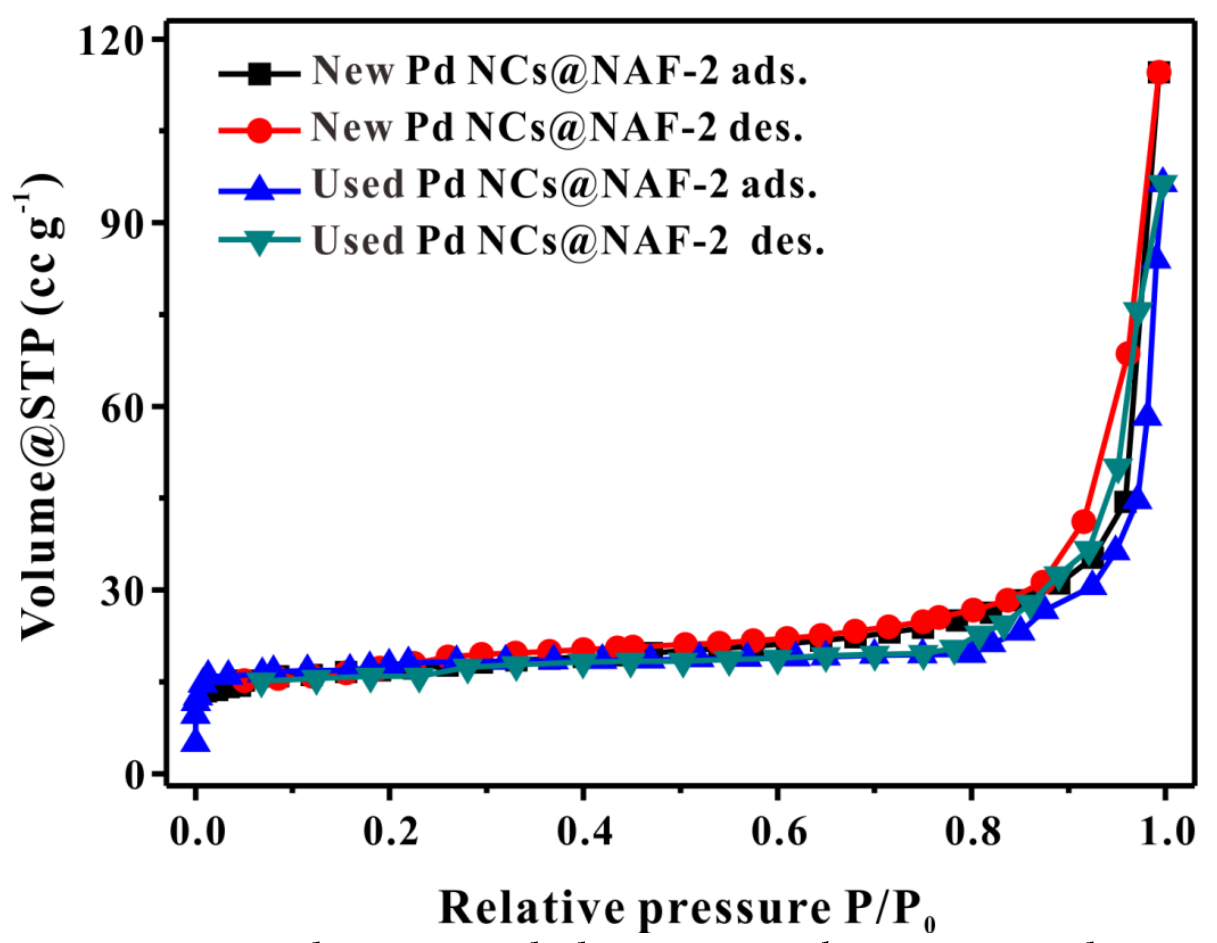

Figure S28. Nitrogen adsorption and desorption isotherms measured at $77 \mathrm{~K}$ of new-synthesized Pd NCs@NAF-2 composites and used Pd NCs@NAF-2 composites. 


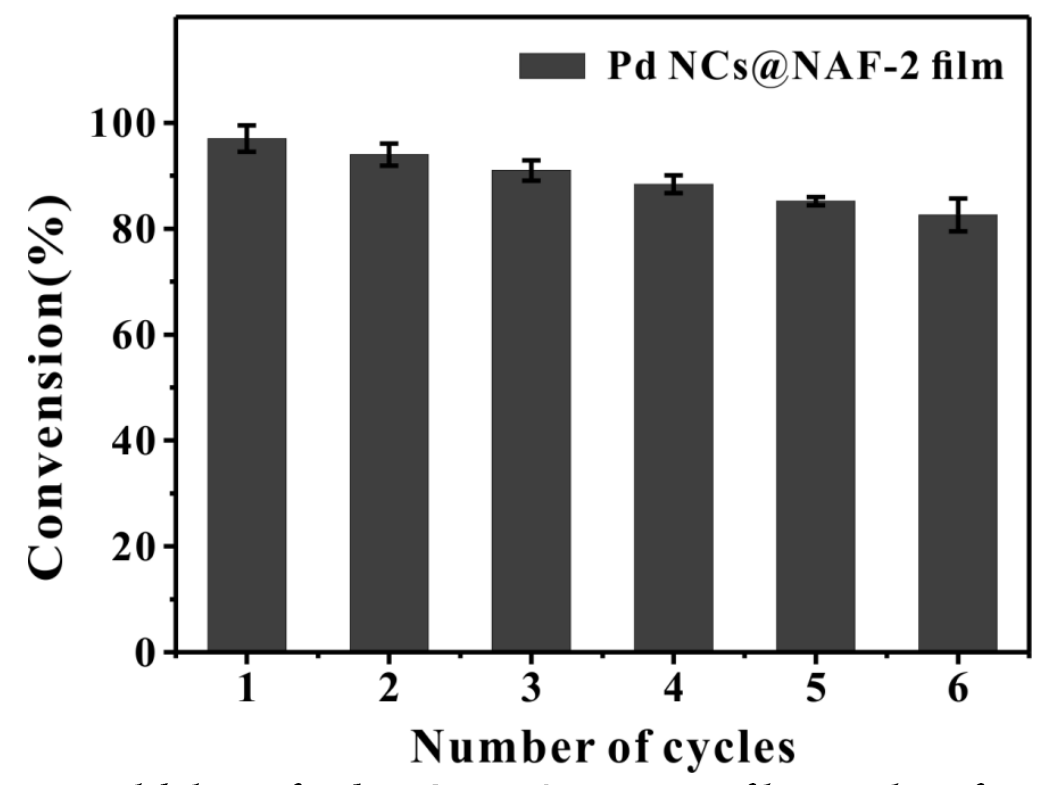

Figure S29. Recyclability of Pd NCs@MOF NAF-2 film catalyst for the $n$-hexene hydrogenation over six consecutive runs.

The possible reason for the slight decrease in the activity of Pd NCs@NAF s after 6 cycles: due to the strong shear force of the fluid, it does bring a very slight damage to the morphology of MOFs nanosheets. So the length-to-spacing ratio of MOF nanosheet has changed, thus leading to decrease in conversion. 
Table S1 Complete results of the nanoindentation test for different MOF films at various load.

\begin{tabular}{ccccc}
\hline Materials & Load (uN) & $\begin{array}{c}\text { Young's modulus } \\
(\mathbf{G P a})\end{array}$ & $\begin{array}{c}\text { Hardness } \\
(\mathbf{G P a})\end{array}$ & $\begin{array}{c}\text { Indentation depth } \\
(\mathbf{n m})\end{array}$ \\
\hline & 27.17 & 0.37 & 201.57 \\
& 15.21 & 0.18 & 295.56 \\
MOF bulk & 16.98 & 0.14 & 334.81 \\
film & 500 & 17.71 & 0.23 & 256.87 \\
& 16.08 & 0.16 & 309.04 \\
& 25.05 & 0.23 & 253.06 \\
& 22.47 & 0.71 & 150.67 \\
\hline Average value & 20.10 & 0.29 & 257.37 \\
\hline & 1.16 & 0.03 & 350.11 \\
& 0.72 & 0.01 & 569.76 \\
MOF & 0.77 & 0.01 & 486.64 \\
nanosheet & 100 & 0.50 & 0.01 & 743.79 \\
film & 0.53 & 0.01 & 535.39 \\
& 0.73 & 0.00 & 893.35 \\
& 0.53 & 0.02 & 449.01 \\
\hline Average value & 0.71 & 0.01 & 575.44 \\
\hline
\end{tabular}


Table S2. Kinetic parameters of phenol red adsorption onto MOF films.

\begin{tabular}{|c|c|c|c|c|c|c|}
\hline \multirow{2}{*}{$\begin{array}{l}\text { Adsorbent } \\
\text { (films) }\end{array}$} & \multirow{2}{*}{$\begin{array}{c}q_{e(\exp )} \\
\left(\mathbf{m g ~ g}^{-1}\right)\end{array}$} & \multicolumn{3}{|c|}{ Pseudo-second-order model } & \multicolumn{2}{|c|}{$\begin{array}{c}\text { pseudo-first-orde } \\
\text { model }\end{array}$} \\
\hline & & $\begin{array}{c}\mathbf{q}_{\mathrm{e}(\mathrm{cal})} \\
\left(\mathrm{mg} \mathrm{g}^{-1}\right)\end{array}$ & $\begin{array}{c}k_{2} \\
\left(\mathrm{~g} \mathrm{mg}^{-1} h^{-1}\right)\end{array}$ & $\mathbf{R}^{2}$ & $\mathbf{k}_{\mathbf{1}}\left(\mathbf{h}^{-1}\right)$ & $\mathbf{R}^{2}$ \\
\hline bulk & 42.31 & 46.71 & 0.0149 & 0.9977 & 0.4005 & 0.9851 \\
\hline NAF-0.5 & 69.85 & 75.36 & 0.0155 & 0.9982 & 0.5979 & 0.9867 \\
\hline NAF-1 & 77.92 & 81.37 & 0.0216 & 0.9994 & 0.4853 & 0.9553 \\
\hline NAF-2 & 80.31 & 81.43 & 0.0781 & 0.9999 & 0.8028 & 0.9808 \\
\hline NAF-3 & 78.46 & 80.13 & 0.0466 & 0.9996 & 0.6594 & 0.9828 \\
\hline
\end{tabular}


Table S3. Olefin hydrogenation reactions catalyzed by Pd NCs@MOF composites.

\begin{tabular}{|c|c|c|c|c|c|c|}
\hline Entry & $\begin{array}{c}\text { Catalysts } \\
\text { (films) }\end{array}$ & $\begin{array}{c}\text { Pd } \\
\text { content } \\
\text { (wt. \%) }\end{array}$ & $\begin{array}{l}\text { Time } \\
(\min )\end{array}$ & $\begin{array}{c}\text { Conversion* } \\
(\%)\end{array}$ & $\begin{array}{c}\text { Dispersion }^{\#} \\
\text { (mol active sites } / \\
\text { mol }_{\text {metal, } \%)}\end{array}$ & $\begin{array}{c}\text { TOF }^{\&} \\
\left(\min ^{-1}\right)\end{array}$ \\
\hline \multicolumn{7}{|c|}{ Substrate: 1-hexene } \\
\hline 1 & MOF NAF & 0 & 90 & 0 & 0 & 0 \\
\hline 2 & Pd@bulk & 7.20 & 90 & $28.5 \pm 2.8$ & 1.6 & 234.79 \\
\hline 3 & Pd@NAF-0.5 & 7.20 & 90 & $67.1 \pm 1.5$ & 1.6 & 552.81 \\
\hline 4 & Pd@NAF-1 & 7.20 & 90 & $84.3 \pm 2.1$ & 1.6 & 694.50 \\
\hline 5 & Pd@NAF-2 & 7.20 & 90 & $97.0 \pm 2.5$ & 1.6 & 799.14 \\
\hline 6 & Pd@NAF-3 & 7.20 & 90 & $92.1 \pm 3.1$ & 1.6 & 758.78 \\
\hline
\end{tabular}

${ }^{*}$ Conversion of olefins was determined by gas chromatography.

${ }^{*} \mathrm{CO}$ chemisorption experiments were used to measure active sites of the catalysts.

\&TOFs were calculated using the following equation:

$$
\text { TOF }=\frac{\text { mole number of converted olefin }(\mathrm{mol})}{\text { active } \operatorname{sites}(\mathrm{mol}) \times \text { time }(\mathrm{min})} .
$$




\section{References}

(1) Zhao, Z.; Deng, Z.; Song, A. An approximation method for the large deflection of cantilever beams. Mech. Pract. 36, 341-344, (2014).

(2) Wang, Y.; Zhao, M.; Ping, J.; Chen, B.; Cao, X.; Huang, Y.; Tan, C.; Ma, Q.; Wu, S.; Yu, Y.; Lu, Q.; Chen, J.; Zhao, W.; Ying, Y.; Zhang, H. Bioinspired design of ultrathin 2D bimetallic metal-organic-framework nanosheets used as biomimetic enzymes. Adv. Mater. 28, 4149-4155, (2016).

(3) Sakamoto, R.; Hoshiko, K.; Liu, Q.; Yagi, T.; Nagayama, T.; Kusaka, S.; Tsuchiya, M.; Kitagawa, Y.; Wong, W.-Y.; Nishihara, H. A photofunctional bottom-up bis(dipyrrinato)zinc(II) complex nanosheet. Nat. Commun. 6, 6713, (2015).

(4) Frisch, M.; Trucks, G.; Schlegel, H.; Scuseria, G.; Robb, M.; Cheeseman, J.; Scalmani, G.; Barone, V.; Mennucci, B.; Petersson, G. J. Gaussian 09, Revision B. 01, Gaussian. Inc., Wallingford, CT, (2010). 